\title{
Photographic Volume Estimation of CPAS Main Parachutes
}

\author{
Eric S. Ray ${ }^{1}$ \\ MRI Technologies (JETS), Houston, TX, 77058
}

\begin{abstract}
Capsule Parachute Assembly System (CPAS) flight tests regularly stage a helicopter to observe inflation of $116 \mathrm{ft} D_{0}$ ringsail Main parachutes. These side views can be used to generate 3-D models of inflating canopies to estimate enclosed volume. Assuming a surface of revolution is inadequate because reefed canopies in a cluster are elongated due to mutual aerodynamic interference. A method was developed to combine the side views with upwardlooking HD video to account for non-circular cross sections. Approximating the cross sections as elliptical greatly improves accuracy. But since that correction requires manually tracing projected outlines, the actual irregular shapes can be used to generate high fidelity models. Compensation is also made for apparent tilt angle. Validation was accomplished by comparing perimeter and projected area with known line lengths and/or high quality photogrammetry.
\end{abstract}

$\mathrm{D}_{\mathrm{o}}$

$\mathrm{D}_{\mathrm{p}}$

e

\section{Nomenclature}

$=$ Semi-major axis of an ellipse

$=$ Semi-minor axis of an ellipse

$=$ Cluster Development Test (series)

= Capsule Parachute Assembly System

$=$ Nominal parachute diameter based on constructed area, $D_{0}=\sqrt{4 \cdot S_{0} / \pi}$

$=$ Projected diameter of a parachute, $D_{p}=\sqrt{4 \cdot S_{p} / \pi}$

$=$ Eccentricity of an ellipse

$=$ Engineering Development Unit

$=$ Flight Analysis and Simulation Tool

$=$ Global Positioning System

$=$ Height

$=$ High Definition (camera)

$=$ Reefing line length

$=$ Length of riser

$=$ Suspension line length

$=$ Number of parachutes in a cluster

$=$ Number of gores in a parachute canopy

$=$ Over-Inflation Control Line

$=$ Permanent Reefing Line

$=$ Humidity-corrected atmospheric density

$=$ Ramp Clear (usually chosen as start of test)

$=$ Cross-sectional projected area of canopy slices

$=$ Serial Number

$=$ Parachute Canopy open reference area based on constructed shape

$=$ Projected frontal canopy area

$=$ Tilt angle of the canopy axis relative to the chase aircraft camera

$=$ Widest canopy profile point on 2-D chase image

$=$ Yuma Proving Ground

\footnotetext{
${ }^{1}$ Analysis Engineer, Aerosciences, Flight Dynamics and GN\&C, 2224 Bay Area Blvd, Houston, TX, AIAA Senior Member.
} 
$\mathrm{U}$ NDERSTANDING the speed of air intake into the Orion Capsule Parachute Assembly System (CPAS) $116 \mathrm{ft} \mathrm{D}_{\mathrm{o}}$ ringsail Main parachute is critical to modeling inflation loads. This paper focuses on how still photos and video are used to estimate canopy volume with time. A companion paper ${ }^{1}$ combines volume with other data to characterize all the drag and momentum terms making up the total inflation load.

Current CPAS simulations using the Flight Analysis and Simulation Tool (FAST) generally match the peak load magnitude of the Mains, but the simulated peak load timing usually occurs much earlier than the actual data, especially during the disreef to full open.

This discrepancy implies a lack of

\section{Introduction}

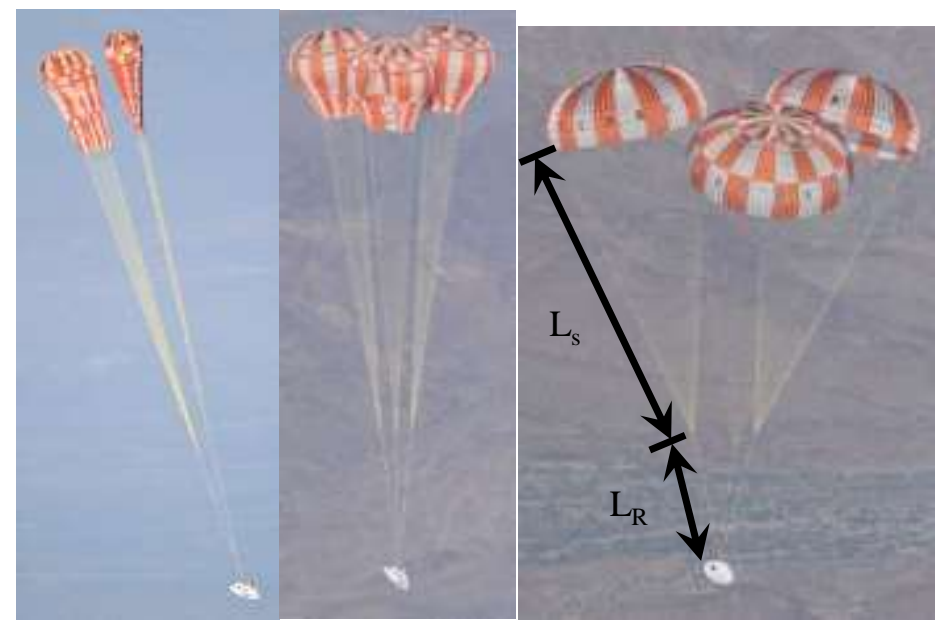

Figure 1. View of CDT-3-13 inflation from YPG chase helicopter.

fidelity in the so-called "added mass" model. ${ }^{2}$ Therefore, an effort was undertaken to better understand Main parachute added mass effects. Added mass can be considered to be comprised of the "enclosed mass" of the air within each canopy and the "apparent mass" of external air affected by viscosity. The enclosed mass is the product of the enclosed air volume and ambient air density $(\rho)$.

Fortunately, a wealth of CPAS Main deployment visual and digital information is available to estimate enclosed mass. On every flight starting with the Engineering Development Unit (EDU) test series, at least one Yuma Proving Ground (YPG) chase helicopter is staged at an altitude to allow for near-profile views of the inflating Main parachutes (Figure 1 and Figure 2). The payload incorporates upward-looking video cameras to observe the inflating shapes and cluster behavior. The avionics system on the payload provides highly accurate system state data $^{3}$ and the Main risers are instrumented for loads. ${ }^{4}$

CPAS has already obtained photogrammetric analysis of upward-looking High Definition (HD) videos for most flights to characterize individual canopy skirt perimeter, maximum projected area $\left(\mathrm{S}_{\mathrm{p}}\right)$, and cluster fly-out angle $(\theta)$ through automated tracking. ${ }^{5,6}$ The additional side views provided by the chase helicopter are necessary to compute volume.

A study of a single Main inflation was conducted early in the test program by Airborne Systems using a ground-based camera to estimate the canopy volume by approximating an ellipsoid shape. ${ }^{7}$ That study indicated that the added mass effects were negligible in the first stage, were more significant in the second stage, and were most significant during the disreef to full open. This matches the current observations. The CPAS Main canopy geometry has since evolved with the addition of a gap and removal of several panels to improve cluster stability. ${ }^{8}$ The current effort also differs from the Airborne study by

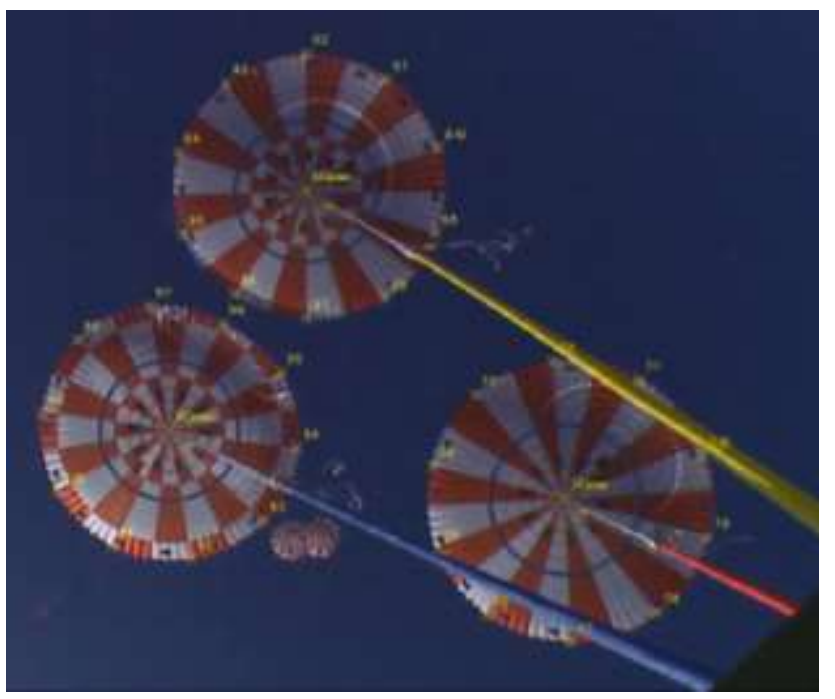

Figure 3. Sample CDT-3-13 KX Main parachute photogrammetric diameter skirt tracking analysis. 
characterizing cluster effects, which often cause the canopies to take irregular shapes due to mutual aerodynamic interference.

In order to perform volume analysis, still photos from the chase aircraft were evaluated for the frequency of image captures. A status summary of volume analysis for Cluster Development Tests (CDT) to date, including any associated chase photo coverage limitations, is presented in Table 1. Early in the test program, the photographers took fewer photographs during the Main parachute phase. They were later encouraged to take more photographs during key deployment and disreef events, especially as the cameras improved and their onboard storage expanded. The final three tests in the EDU series incorporated either Over-Inflation Control Lines (OICL) or Permanent Reefing Lines (PRL) in an effort to control pendulum motion. Because the final design does not include such skirt restrictions, those tests are of lower priority for study. ${ }^{9}$

Table 1. Summary of CPAS Main Volume Analysis

\begin{tabular}{|c|c|c|c|c|c|}
\hline \multirow{2}{*}{ Test } & \multirow{2}{*}{ Vehicle } & \multicolumn{3}{|c|}{ Main Volume Analysis Status } & \multirow{2}{*}{ Notes } \\
\hline & & Bay B & Bay C & Bay E & \\
\hline CDT-2-2 & Weight Tub & \multicolumn{3}{|c|}{ Not enough photos } & Gen II with Added Porosity \\
\hline CDT-2-3 & Weight Tub & \multicolumn{3}{|c|}{ Not enough photos } & Gen II with Added Porosity \\
\hline CDT-3-1 & PCDTV & Not Visible & Sparse & Sparse & Upward-looking HD cameras failed \\
\hline CDT-3-2 & PCDTV & N/A & Complete & Complete & \\
\hline CDT-3-3 & PTV & Sparse & Not Visible & Sparse & Very few photos in $2^{\text {nd }}$ and full open \\
\hline CDT-3-4 & PCDTV & Skip $2^{\text {nd }}$ & Not Visible & Complete & Bay B skip $2^{\text {nd }}$ stage \\
\hline CDT-3-5 & PTV & Sparse & Sparse & Sparse & Bay B skip $1^{\text {st }}$ stage \\
\hline CDT-3-6 & PCDTV & Complete & Complete & Complete & No photogrammetry for validation \\
\hline CDT-3-7 & PTV & Complete & Complete & Complete & Bay B obscured during full open \\
\hline CDT-3-8 & PCDTV & Flagging mod. & Complete & Complete & Sparse early; Chase helo above Mains \\
\hline CDT-3-9 & PTV & Skip $1^{\text {st }}$ & Complete & Complete & Bay E obscured in $1^{\text {st }}$ stage \\
\hline CDT-3-11 & PTV & Skip, cut & Sparse & Sparse & Bay B not visible; Gaps between stages \\
\hline CDT-3-10 & PTV & Complete & Complete & Complete & Bay C obscured during full open \\
\hline CDT-3-12 & PCDTV & N/A & Complete & Complete & \\
\hline EFT-1 & Orion $\mathrm{CM}$ & \multicolumn{3}{|c|}{ Insufficient Coverage } & \\
\hline CDT-3-13 & PTV & Complete & Complete & Complete & Bay B obscured in $1^{\text {st }}$ stage \\
\hline CDT-3-14 & PTV & Skip $2^{\text {nd }}$ & Complete & Complete & Bay B skip $2^{\text {nd }}$ stage; Chase above \\
\hline CDT-3-15 & PTV & N/A & Complete & Complete & OICL and shorter riser \\
\hline CDT-3-16 & PTV & Pending & N/A & Pending & Sparse coverage in early stages; PRL \\
\hline CDT-3-17 & PCDTV & Pending & Pending & Pending & PRL \\
\hline
\end{tabular}

The still photographs contain metadata such as camera settings, the time of digitization, and can include GPS data. However, the image capture times were not synchronized to absolute time. A method was developed to compute exact shutter times using the relative timestamps and key photos at known events (such as disreef and touchdown). This method was used to synchronize over-inflation angles derived from chase photos to inflation load cell measurements to estimate the tension in reefing lines. ${ }^{10}$

The various methods for estimating volume are discussed in Section II and selected flight test results are presented in Section III.

\section{Methodology}

The overall process of estimating 3-D parachute volume involves combining 2-D shapes with viewpoints from two different directions. The steps are summarized in a flowchart in Figure 4. The process involves considerable manual user interaction to select or "score" visible points on an image-by-image basis. Because the process can be time consuming, efforts were made up front to streamline the workflow process. The images are read into MATLAB and processed using a series of scripts. The user is provided with visual feedback to determine the accuracy of the selected points and is given the option to re-do this task if necessary. In order to avoid needless replication, the userdefined data are saved at several incremental steps. This allowed for fast re-processing of the data as the algorithms improved.

American Institute of Aeronautics and Astronautics 


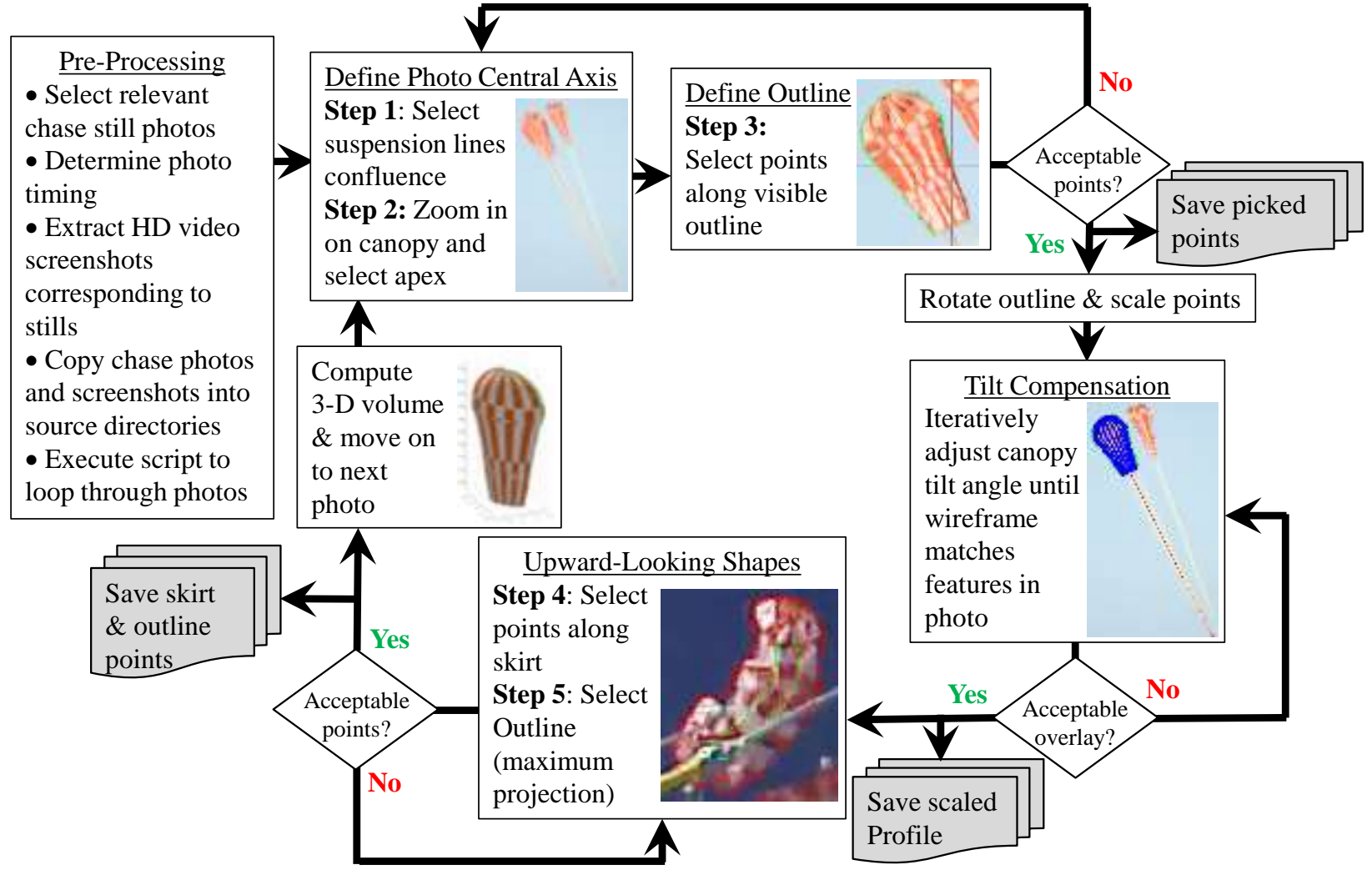

Figure 4. Volume estimation process flowchart.

\section{A. Geometry Selection from Chase Photograph}

The coordinate system of each canopy is defined such that the Z-direction is along the central axis. As shown in Figure 5, this axis is defined by two points selected by the user: the confluence of suspension lines (Step 1) and the canopy apex (Step 2). The user is prompted to zoom in on each of these features for accuracy. This first example presented (Main S/N 9 on CDT-3-13) is for a canopy where the semi-major axis is presented to the camera. A later example explains the process for a canopy where the semi-minor axis is visible. The user is prompted to choose which orientation is more appropriate. At present, there is no provision for intermediate roll orientations. 


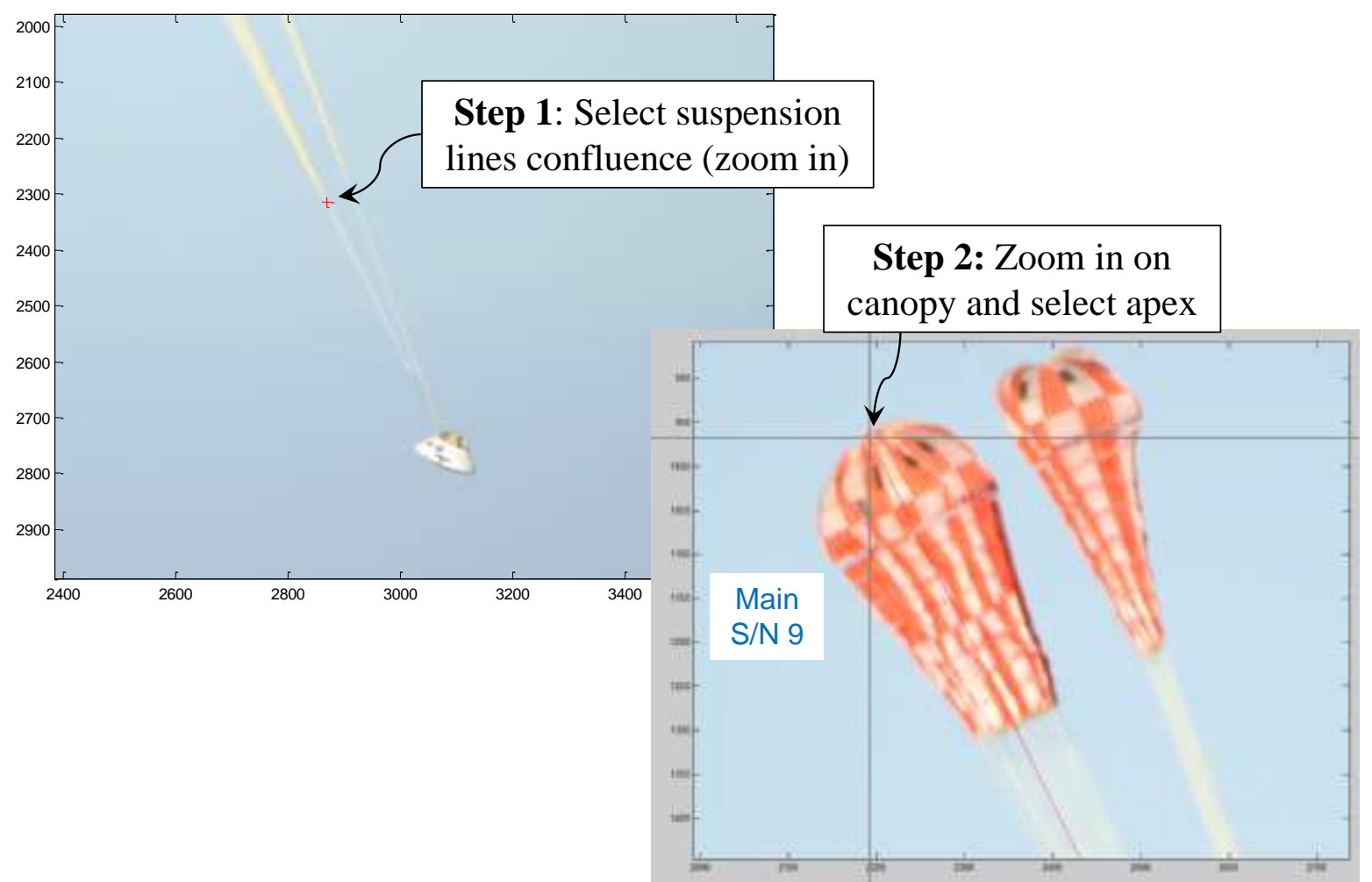

Figure 5. Select points to define canopy central axis.

Step 3 is to define the canopy outline from the side view, as shown in Figure 6. As many points as desired may be used, limited only by monitor resolution. If the canopy is partially obscured, points need only be defined for one side of the centerline or the other. By always proceeding in a clockwise direction, the user does not need to specify which side is being defined. Ideally, the user will select points along the entire outline, and the code will separate them according to their relationship to the central axis, in order to compute an average shape. An average shape is then computed from the profile halves, providing a smoother

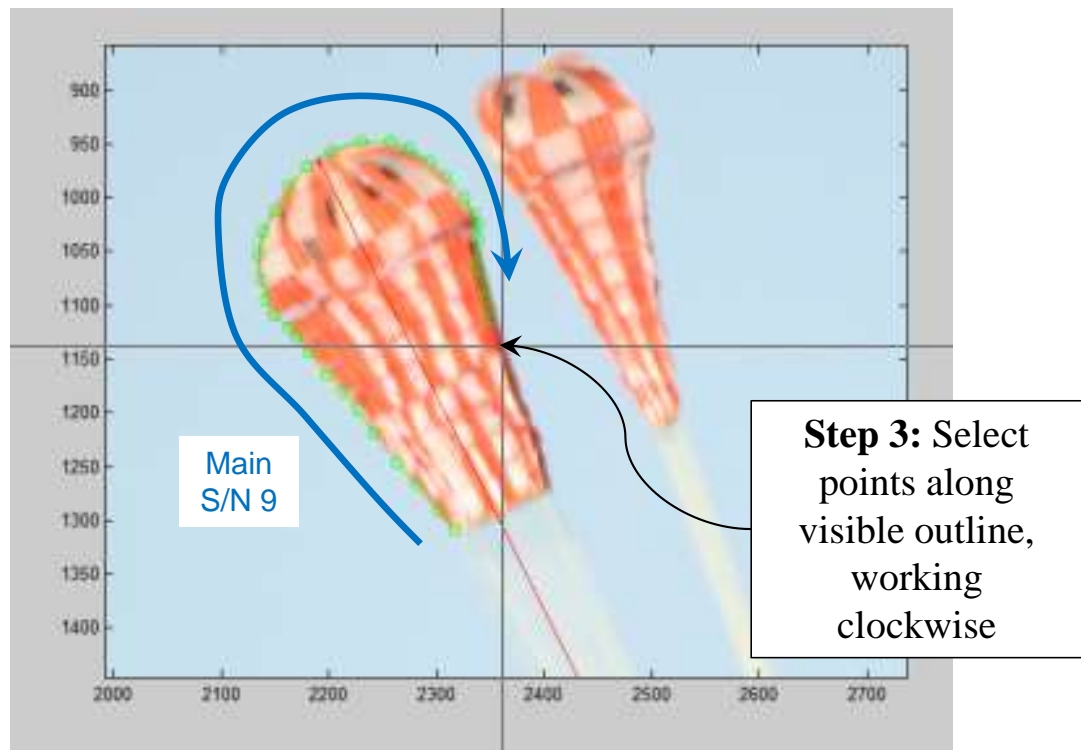

Figure 6. Selection of canopy outline. surface than a single side would.

If the user is satisfied with the scoring, the coordinates for all selected points are then saved to a data file. The pixel location data for each image are saved in a separate worksheet (named according to the chase photo) in an Excel spreadsheet for the given canopy and test.

The profile points are then rotated within the image plane to a coordinate system where $\mathrm{Z}$ is aligned to the central axis, as shown on the left of Figure 7. At this stage, it is necessary to provide a finer resolution to each side of the outline shape. During script development, it was discovered that the built-in MATLAB spline fitting tools were inadequate for this purpose. It was difficult to ensure monotonically increasing abscissa values did not have doubly-

American Institute of Aeronautics and Astronautics 
defined ordinates. Using Cartesian sample points in either direction would result in clustering of points at either the apex or skirt, with undesirable low resolution at the other end. Fortunately, a member of the MATLAB community had created the "interparc" function, which was employed successfully to distribute interpolated points with desired spacing based on 2-D arc length. ${ }^{11}$ When both sides were available, an average was computed, in order to produce a smoother profile. The selected points, interpolation, and averaged profiles are overlaid in the upper right image. Because the suspension line lengths were known, the distance between the origin (suspension line confluence) and skirt edges was then used to compute a scale factor from image pixels to actual size (in feet) for the given frame. The scaled average profile is shown in the lower right. The transformed 2-D profile points are saved to a unique worksheet in another Excel data file.
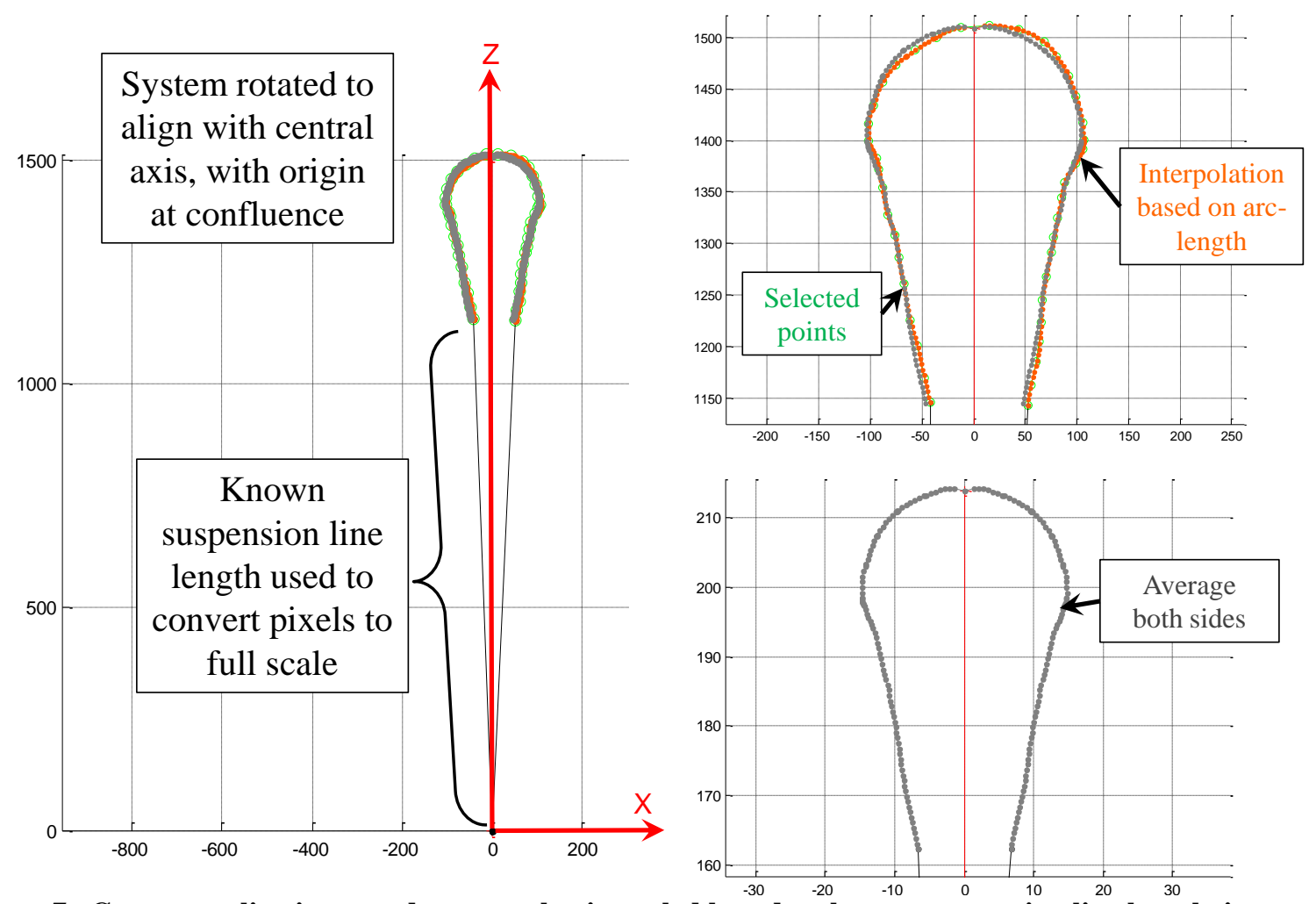

Figure 7. Canopy outline is rotated to central axis, scaled based on known suspension line length, interpolated to a finer resolution based on arc-length, and averaged across both sides.

\section{B. Circular Cross-Section Volume Approximation}

Once a side profile was available, an initial attempt at estimating the canopy volume was made by creating a surface of revolution by rotating the profile around the central axis, as illustrated in Figure 8. The volume is computed as a summation of horizontal slices, where each slice is approximated as a truncated cone. The area of the bottom surface $\left(S_{i}\right)$ and top surface $\left(S_{i+1}\right)$ are computed from circles of radii of $X_{i}$ and $X_{i+1}$, respectively. The height of each slice is the difference between $Z_{i+1}$ and $Z_{i}$. 


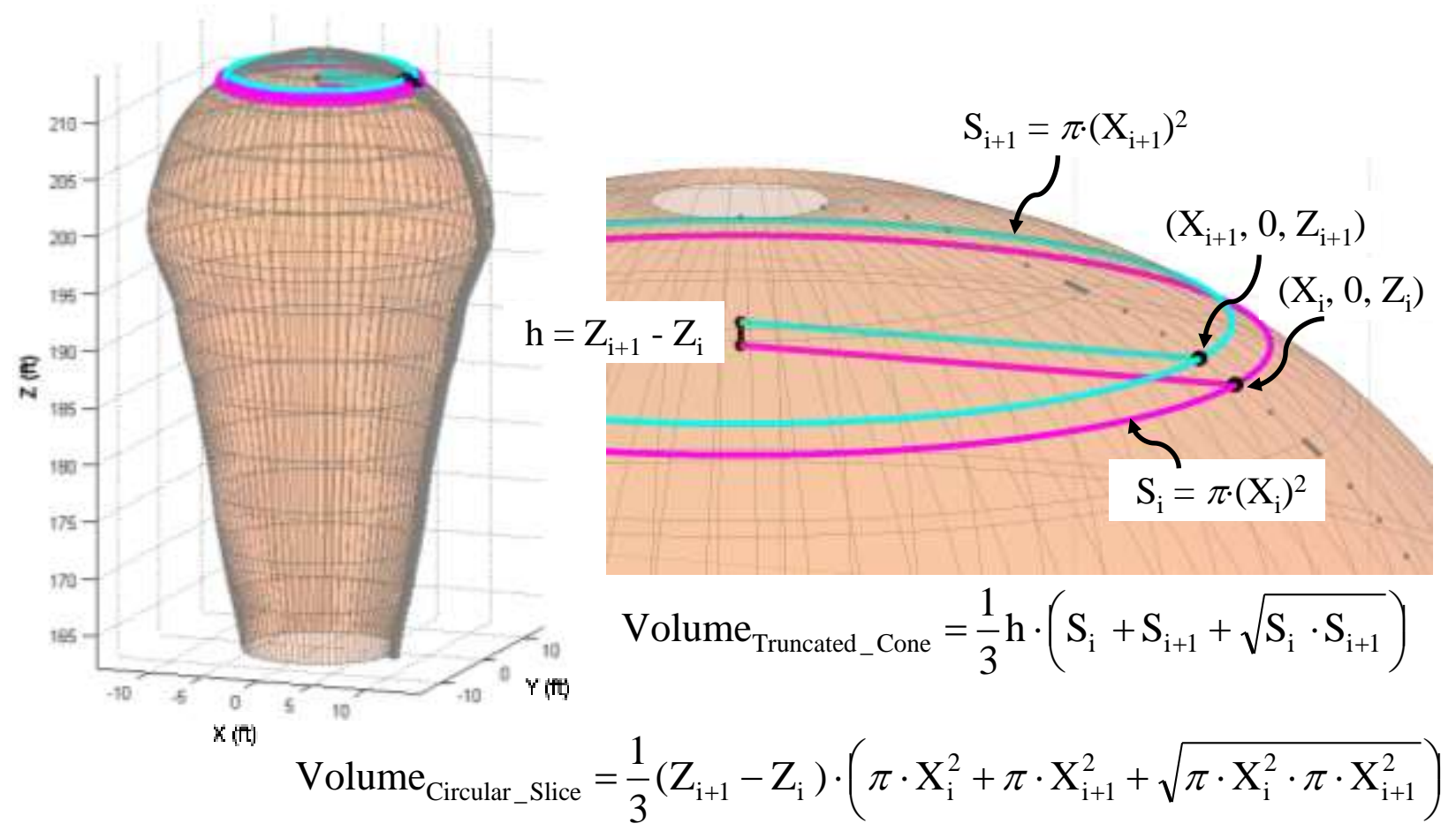

Figure 8. Volume slice for circular surface of revolution.

The total volume is computed according to Eq. (1). The summation does not include the uppermost slice, which represents the vent.

$$
\text { Volume }_{\text {Circular }}=\frac{\pi}{3} \sum_{\mathrm{i}=1}^{\mathrm{N}-2}\left(\mathrm{Z}_{\mathrm{i}+1}-\mathrm{Z}_{\mathrm{i}}\right) \cdot\left(\mathrm{X}_{\mathrm{i}}^{2}+\mathrm{X}_{\mathrm{i}+1}^{2}+\sqrt{\mathrm{X}_{\mathrm{i}}^{2} \cdot \mathrm{X}_{\mathrm{i}+1}^{2}}\right)
$$

Where $\mathrm{N}=$ number of interpolated profile points

In order to aid in visualization, the specified query points for the arc length interpolation were chosen to correspond to features of the CPAS Main gore layout, shown on the left of Figure 9. An equal number of points were used to represent each ring, gap, and sail, in order to highlight these features. The radial layout was replicated across all 80 gores $\left(\mathrm{N}_{\mathrm{G}}\right)$, and the color scheme for the given canopy was applied to each panel. Physical gaps and the windows along every fifth panel of sail 7 were represented by setting the opacity (alpha value) of the relevant panels to zero.

American Institute of Aeronautics and Astronautics 


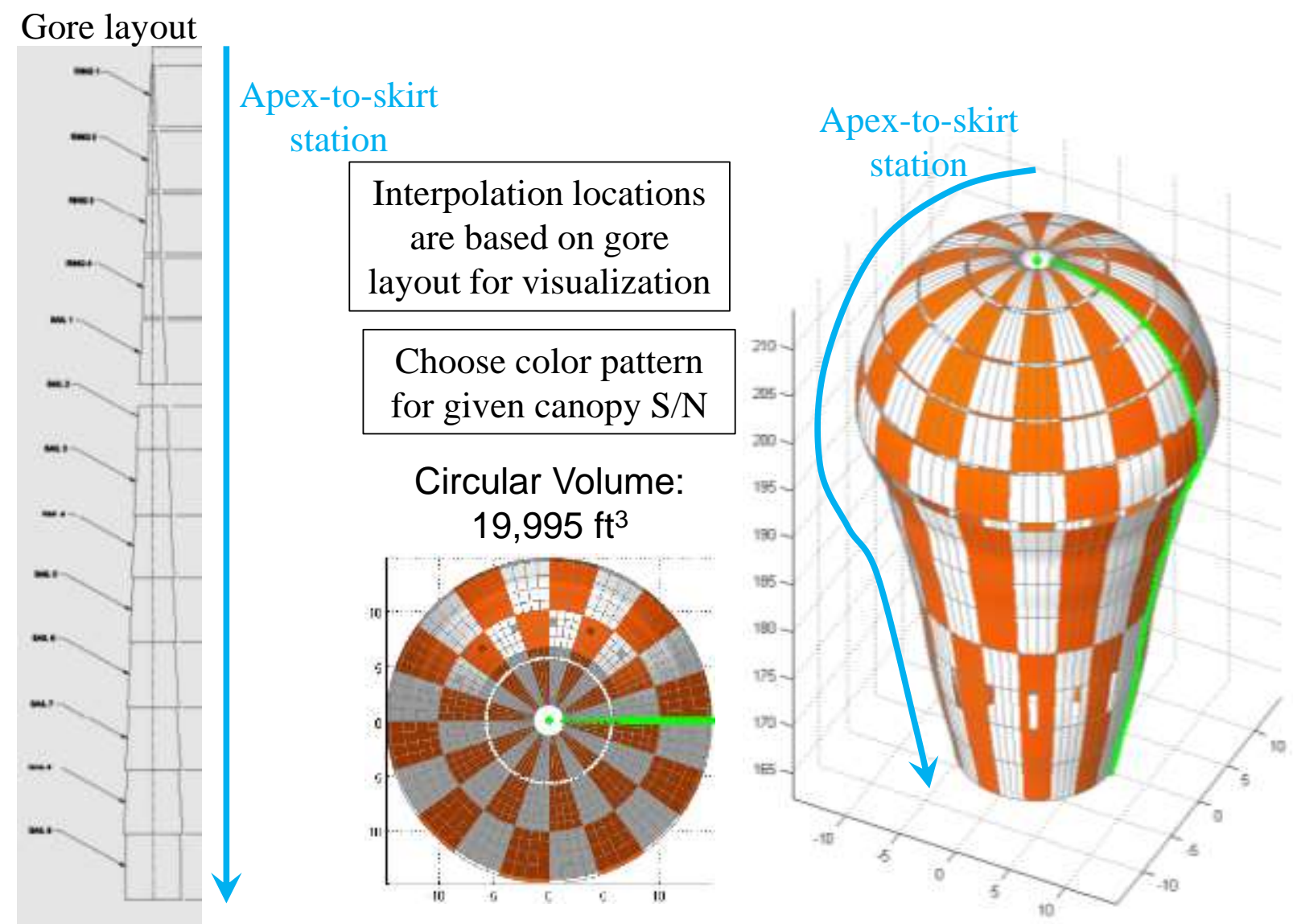

Figure 9. The interpolation spacing is based on the known gore layout (left), so that vent, gaps, radials, and sails will be distinguishable in the 3-D rendering (right).

In this case, the circular volume of about 20,000 cubic feet seemed unreasonably high for a reefed canopy in a cluster. The volume from Ref. 7 was on the order of 8,000 cubic feet for first stage. A more accurate volume estimate requires a view from an upward-looking camera to derive the actual shape via additional steps.

\section{Elliptical Cross-Section Volume Approximation}

Most CPAS flight tests successfully recorded two HD videos with overlapping views. Because the HD cameras have a rectangular aspect ratio, as illustrated in Figure 10, the cameras were installed with different clocking so at least one would observe any canopy with a large fly-out angle. For each still chase photo, a frame was extracted from the time-synchronized video with the best coverage for the given canopy and saved as a JPEG image, where the filename includes the name of the still photo. This process was originally done manually using a video player and later automated in MATLAB. The JPEG image is then read into MATLAB to be scored by the user.

The user is prompted to zoom in on the canopy and select as many points as desired along the skirt of the canopy of interest (usually identified by the coloring of the protective riser sheathing). The points selected are plotted in green in Figure 11.

After the skirt shape is defined, the user selects points that define the outline, or maximum projected area, of the canopy. These points are shown in red in Figure 12. The pixel coordinates for both 2-D outlines

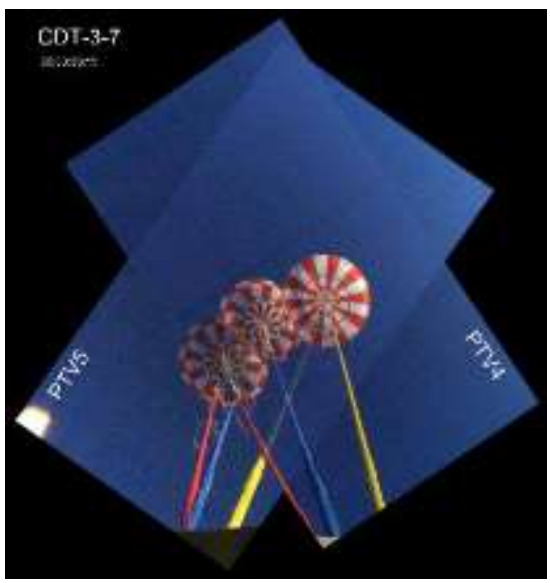

Figure 10. Sample of overlapping HD camera coverage. 
are then saved to a worksheet in another Excel data file. Using different data files allows the user the option to re-score either the side view or bottom view and recompute volume, without affecting the other user-defined data.

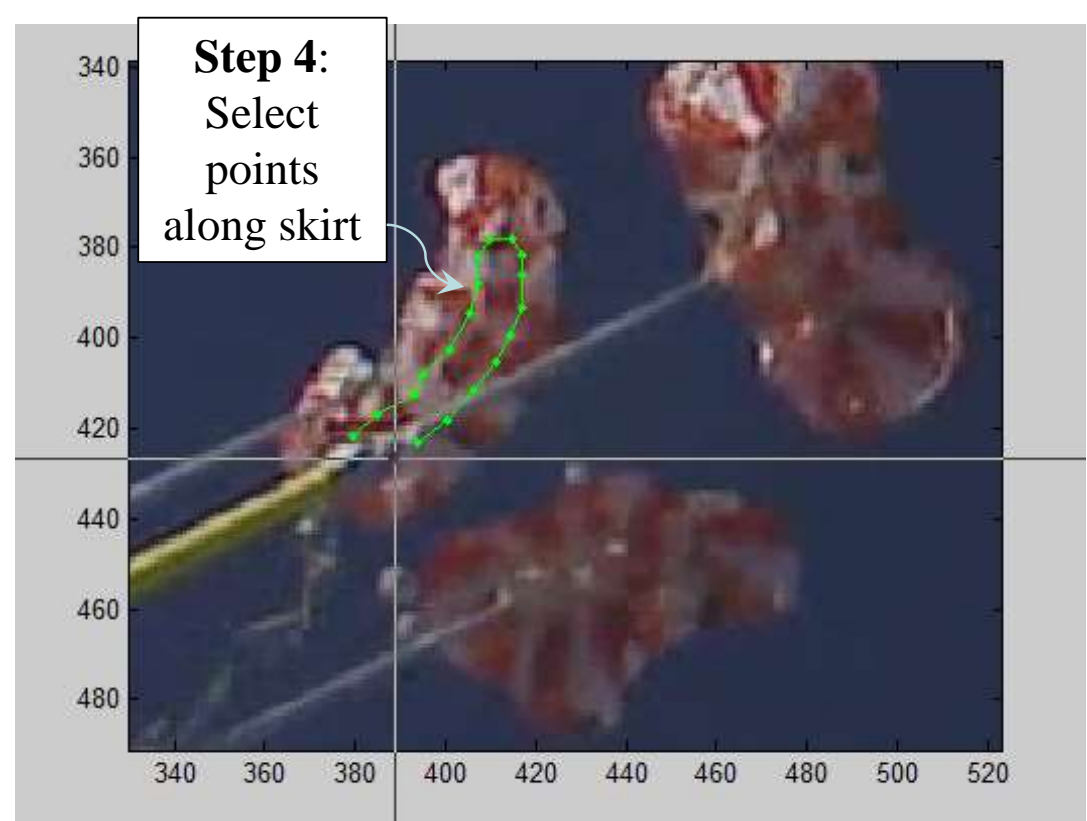

Figure 11. Selection of skirt points from upward-looking video frame.

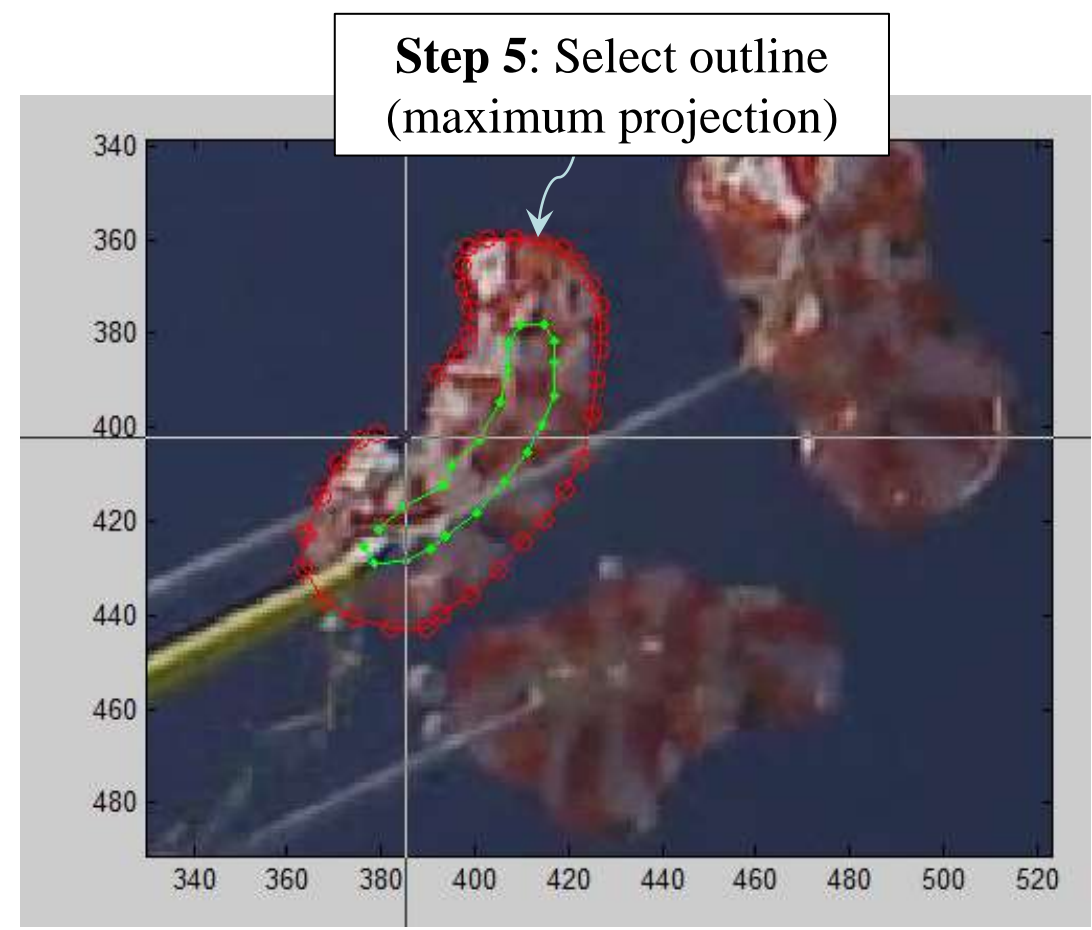

Figure 12. Selection of maximum projected area.
Because the canopies in the cluster are elongated due to aerodynamic interference, the geometry assumption was changed from a circular to an elliptical cross section. The elliptical semi-major axis (a), semi-minor axis (b), and eccentricity (e) are computed using a least-squares method with the "fitellipse" function, submitted by a member of the MATLAB community. ${ }^{12}$

The updated 3-D shape is presented in Figure 13. The elliptical dimensional parameters for the skirt ( $a_{\text {skirt }}$ and $\mathrm{b}_{\text {skirt}}$ ) are scaled from pixels to feet according to the skirt radius $\left(\mathrm{X}_{\mathrm{i}=1}\right)$ previously established from the side views. In this case, it is assumed that the skirt radius from the side image is associated with the semi-major axis. This same scale factor is applied to the maximum projection

elliptical data. The point with the largest radius $\left(\mathrm{X}_{\mathrm{MAX}}\right)$ in the side profile is then associated with the maximum projection to determine the elliptical parameters at that $\mathrm{Z}$ location $\left(\mathrm{a}_{\max }\right.$ and $\left.\mathrm{b}_{\max }\right)$. The semi-major axis at each slice is equivalent to the $\mathrm{X}$ coordinate from the profile. The semi-minor axis (or Y coordinate in the X-Y plane) is computed from the definition of eccentricity. Eccentricity is linearly interpolated with $\mathrm{Z}$ between the skirt and maximum projection. It is assumed that the eccentricity above the maximum projection is identical to that of the maximum projection all the way to the apex.

American Institute of Aeronautics and Astronautics 


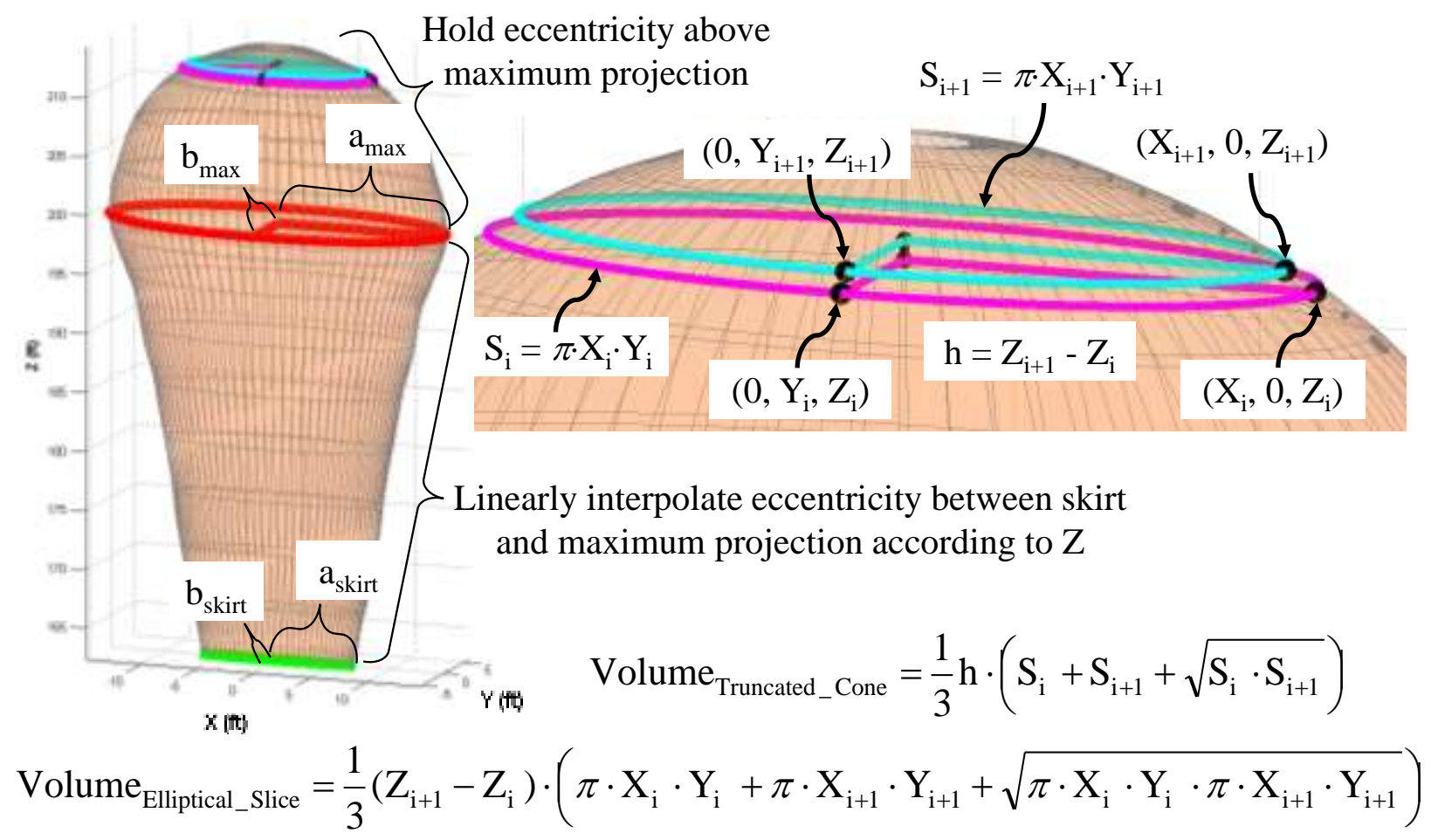

Figure 13. Volume slices for elliptical cross-sectional geometry.

The volume of each slice is again computed using the equation of a truncated cone. The areas on the top and bottom of each slice are computed using the elliptical equation of $\pi \cdot a \cdot b$. The total volume is the summation of the slices according to Eq. (2).

$$
\text { Volume }_{\text {Elliptical }}=\frac{\pi}{3} \sum_{\mathrm{i}=1}^{\mathrm{N}-2}\left(\mathrm{Z}_{\mathrm{i}+1}-\mathrm{Z}_{\mathrm{i}}\right) \cdot\left(\mathrm{X}_{\mathrm{i}} \cdot \mathrm{Y}_{\mathrm{i}}+\mathrm{X}_{\mathrm{i}+1} \cdot \mathrm{Y}_{\mathrm{i}+1}+\sqrt{\mathrm{X}_{\mathrm{i}} \cdot \mathrm{Y}_{\mathrm{i}} \cdot \mathrm{X}_{\mathrm{i}+1} \cdot \mathrm{Y}_{\mathrm{i}+1}}\right)
$$

The resulting geometry for this example is shown in Figure 14. The elliptical curve fit at the skirt is less than ideal, because it is much more elongated than the actual shape. The enclosed volume estimate using elliptical cross sections is about $1 / 3$ that of using circular cross sections. 


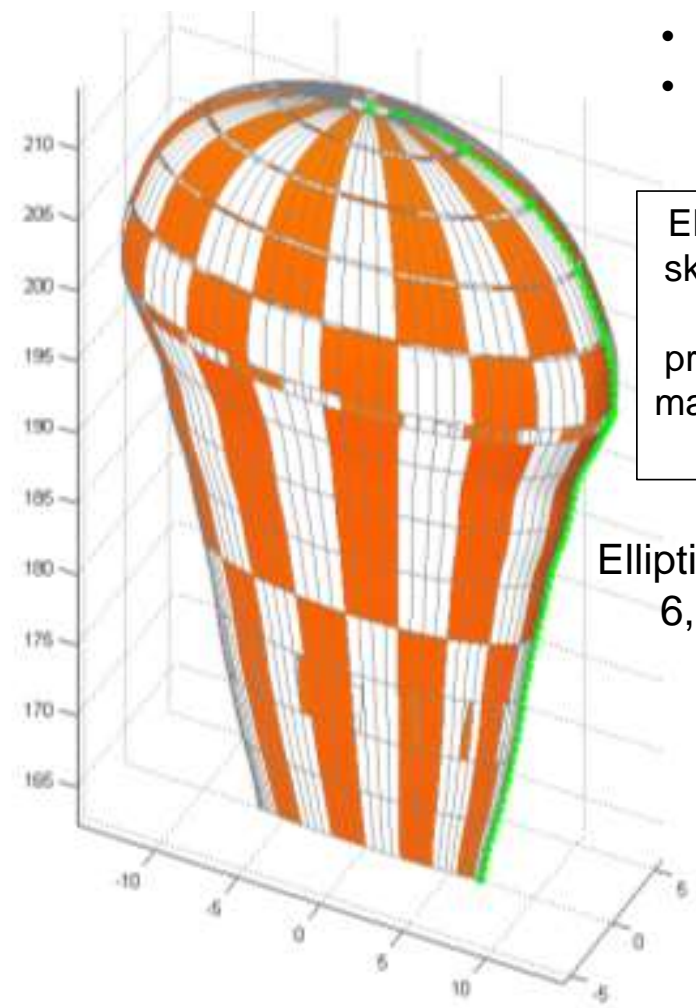

- Cannot account for concavities

- Skirt usually extremely elongated
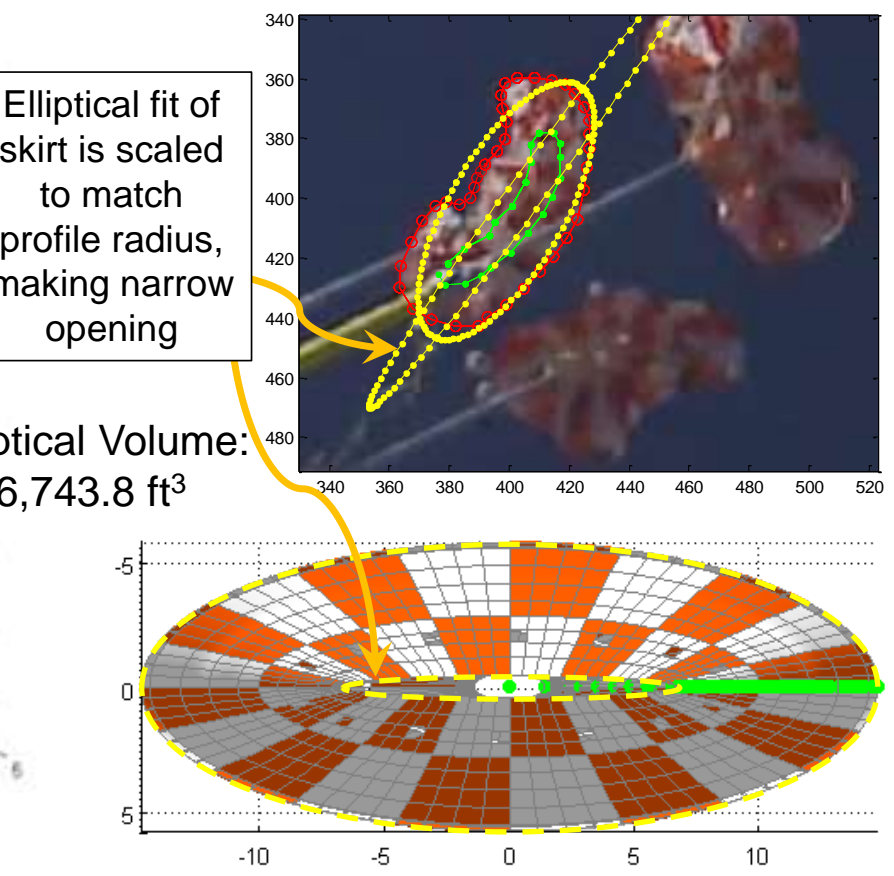

Figure 14. Volume estimate using elliptical cross-section approximation.

For much of a typical inflation, the elliptical method provides a reasonable first order approximation of the actual volume. However, extremely asymmetrical shapes can create distortions in the elliptical curve fits, even resulting in failures to converge. Due to the limitations of the elliptical method, an alternative method of computing 3-D geometry was developed which could be applied to the same user-gathered data.

\section{Irregular Cross-Section Volume Computation Using Semi-Major Axis}

With the skirt and maximum projection boundaries having been defined previously, it is not necessary to approximate those shapes as ellipses or other primitive shapes. The elliptical method established how to "blend" the skirt shape to the maximum projection as a function of Z. It was therefore possible to blend the actual geometry between those horizontal planes to create an irregular 3-D shape. Because the upper portion of the canopy is not visible from below, it was also assumed that the shape of the maximum projection would be unchanged above that plane, but with each slice scaled according to the profile view.

Sample irregular cross-sections are shown for this example in Figure 15. Because the rotation angle of the canopy in the upward-looking image is random, the skirt and maximum projection outlines are not aligned with any particular axis. For a case where the side view observed the semi-major axis, it is assumed that the profile points should be aligned with the long axis. This axis was determined by computing the distance from the centroid to each perimeter point in the maximum projection plane and identifying the largest radial distance $\left(r_{\max }\right)$. The profile points were then rotated according to the angle defined by the maximum radius.

American Institute of Aeronautics and Astronautics 


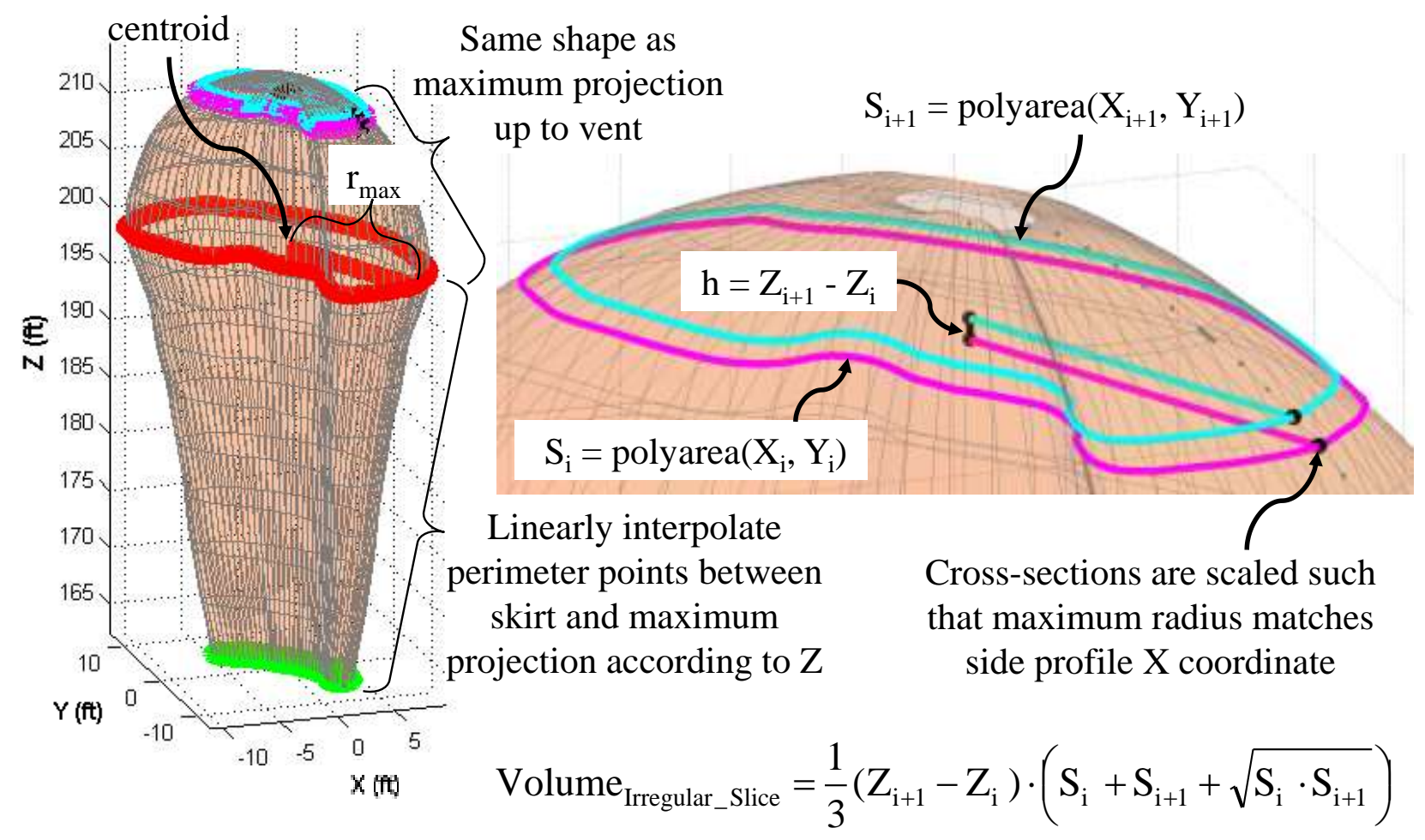

Figure 15. Volume slices for irregular cross-sectional geometry.

The equation for the volume of each slice is analogous to the truncated cone equation. The areas of the top and bottom of each slice are computed using the built-in MATLAB "polyarea" function. The total volume is the summation of the slices according to Eq. (3).

$$
\text { Volume }_{\text {Irregular }}=\frac{1}{3} \sum_{\mathrm{i}=1}^{\mathrm{N}-2}\left(\mathrm{Z}_{\mathrm{i}+1}-\mathrm{Z}_{\mathrm{i}}\right) \cdot\left(\mathrm{S}_{\mathrm{i}}+\mathrm{S}_{\mathrm{i}+1}+\sqrt{\mathrm{S}_{\mathrm{i}} \cdot \mathrm{S}_{\mathrm{i}+1}}\right)
$$

The resulting geometry for this example is shown in Figure 16 . The total volume is about $22 \%$ higher than the elliptical cross-section approximation. 


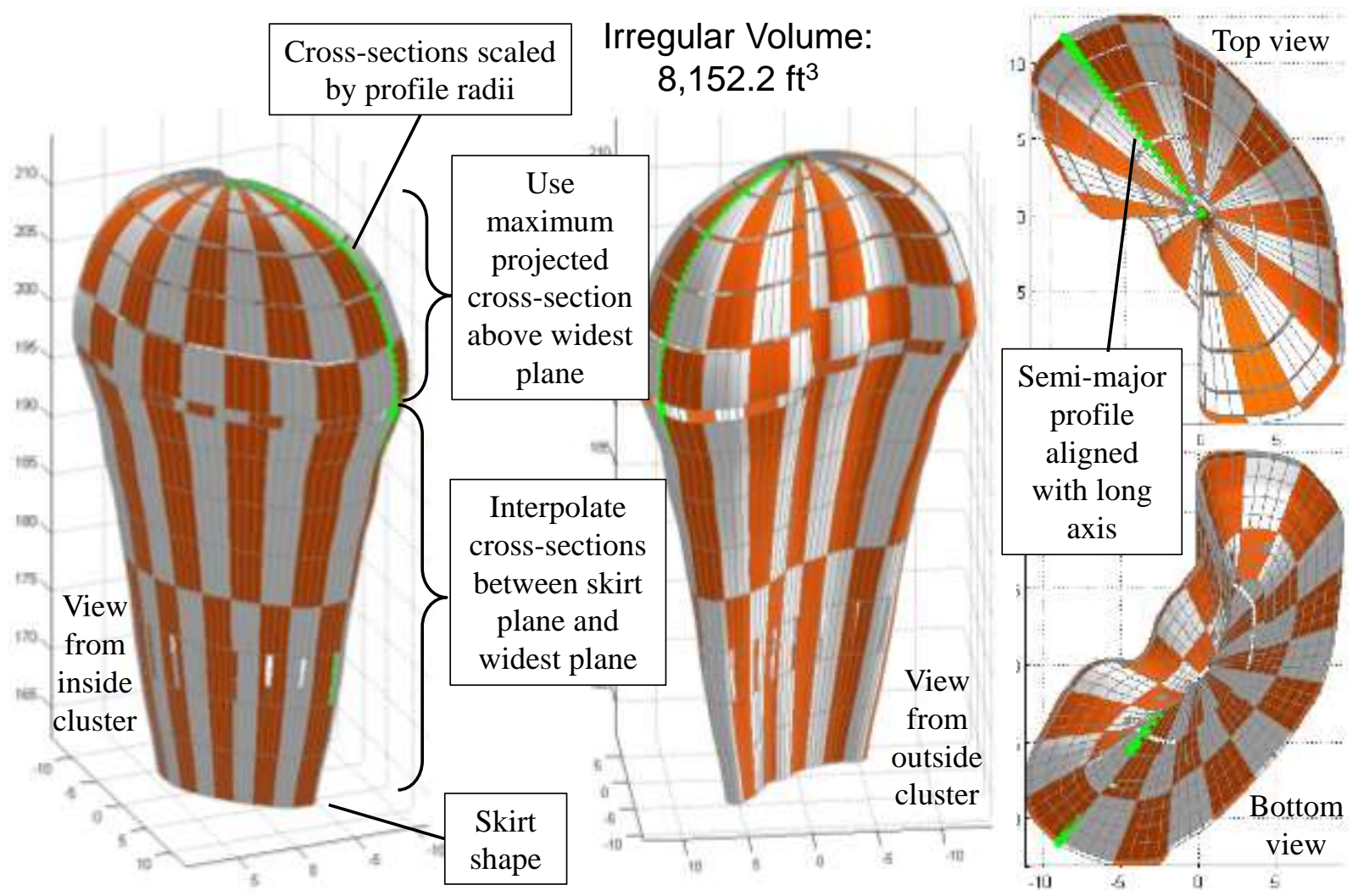

Figure 16. Volume estimate using irregular cross-section approximation.

The 3-D geometry from this method is compared to the original images for several instants during the disreef to full open in Figure 17 through Figure 19. Because the 3-D surface appears much closer to the original images than circular and elliptical approximate methods, the volume data for each flight test were computed using the irregular shape method. 

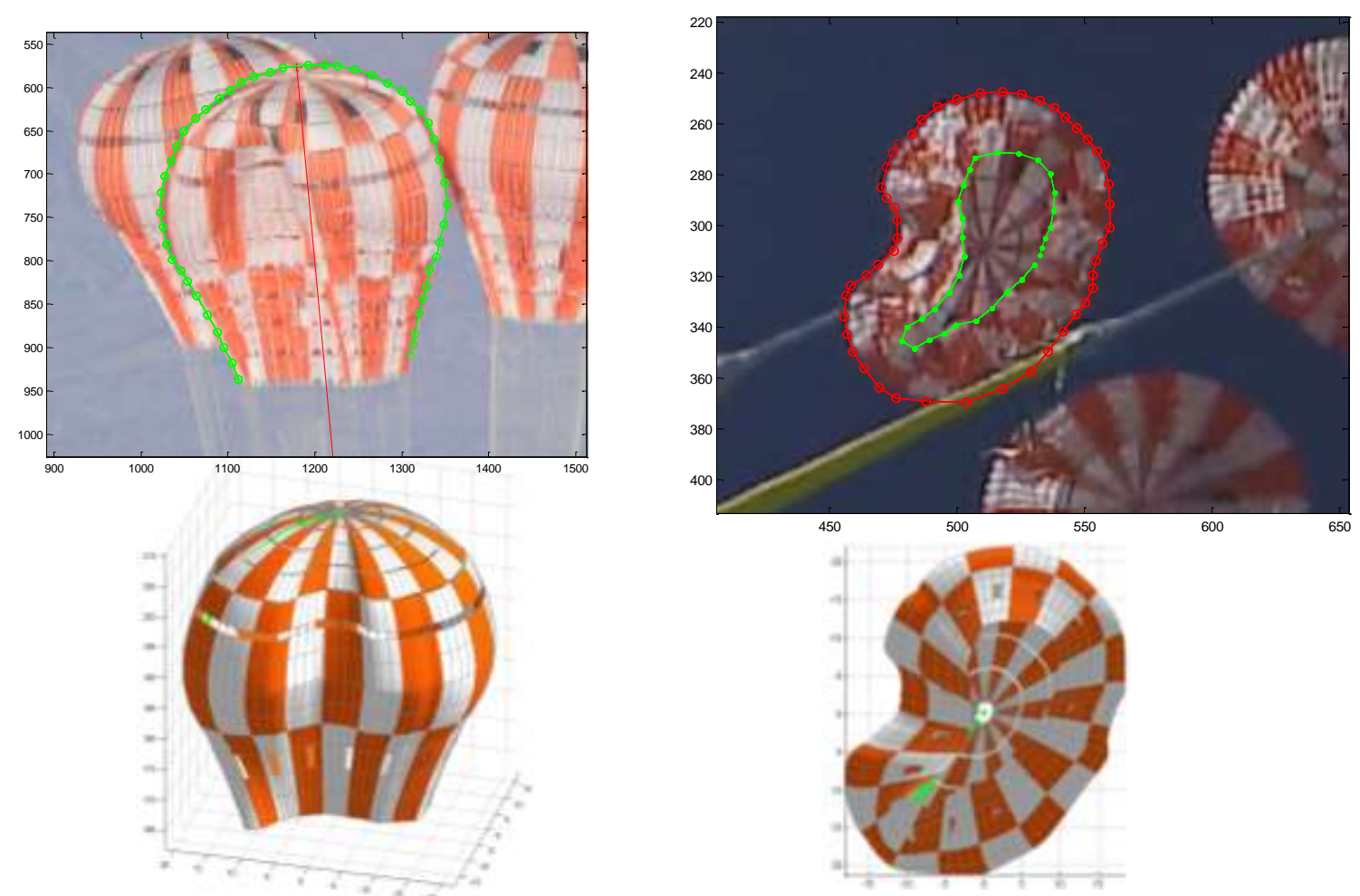

Figure 17. Model of irregular geometry of S/N 9 during second stage.
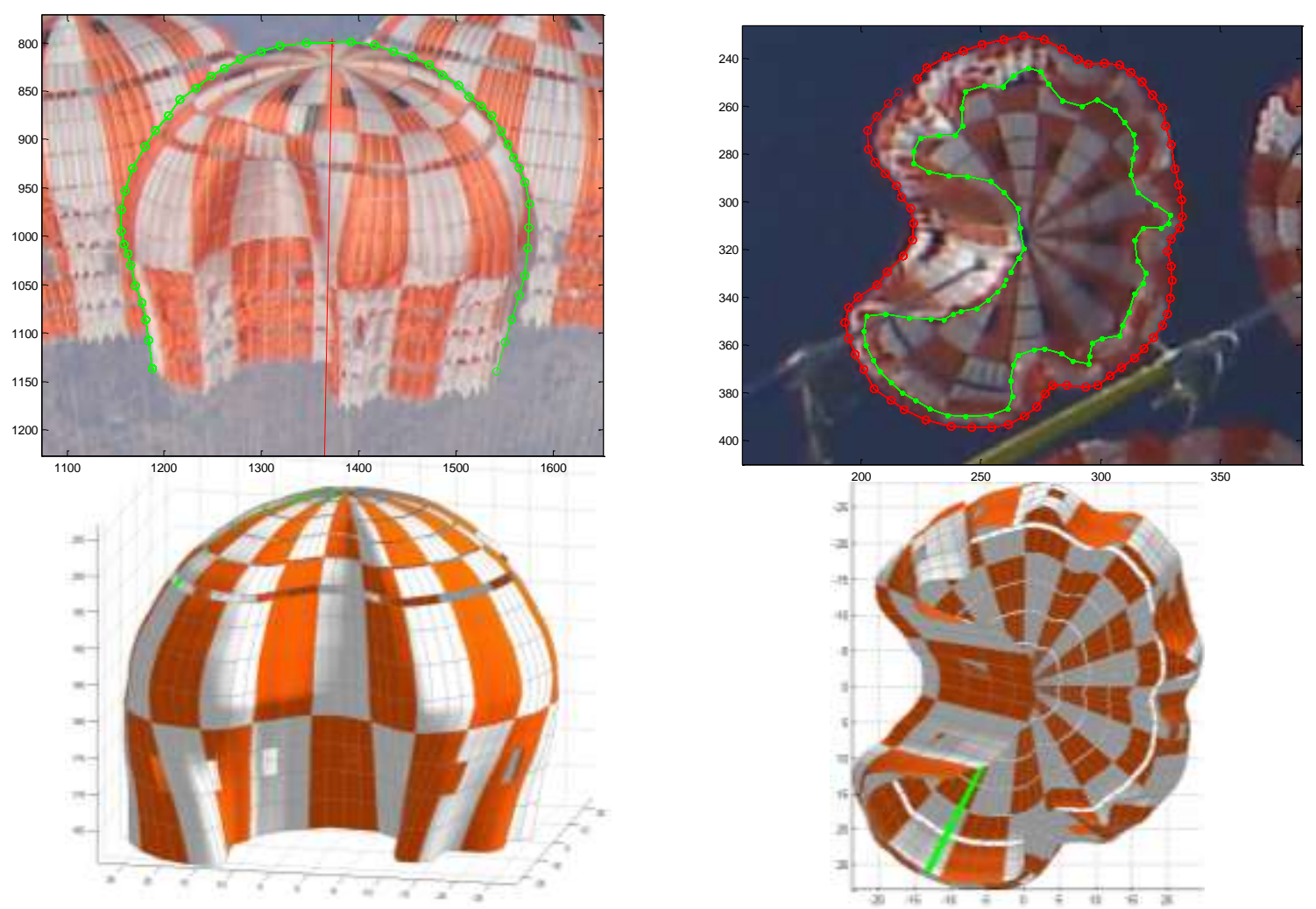

Figure 18. Model of irregular geometry of $\mathrm{S} / \mathrm{N} 9$ during disreef to full open. 

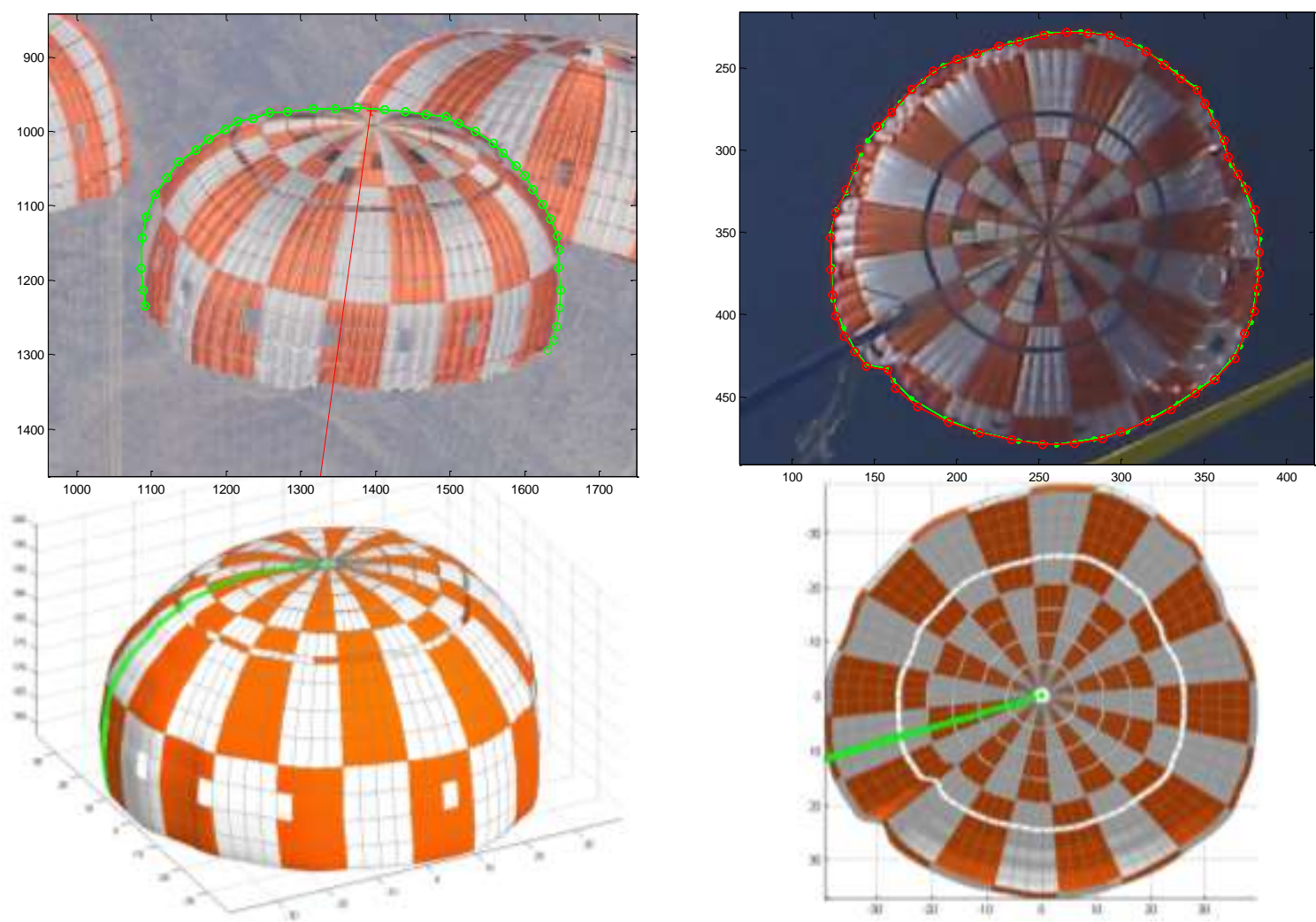

Figure 19. Model of irregular geometry of S/N 9 at full open.

\section{E. Volume Estimates Using Semi-Minor Axis}

If an elongated canopy presents its semi-minor axis, such as Main S/N 8 on CDT-3-13 seen in Figure 20, the steps in the scoring method are similar to the previous example. However, the volume algorithm has been modified.

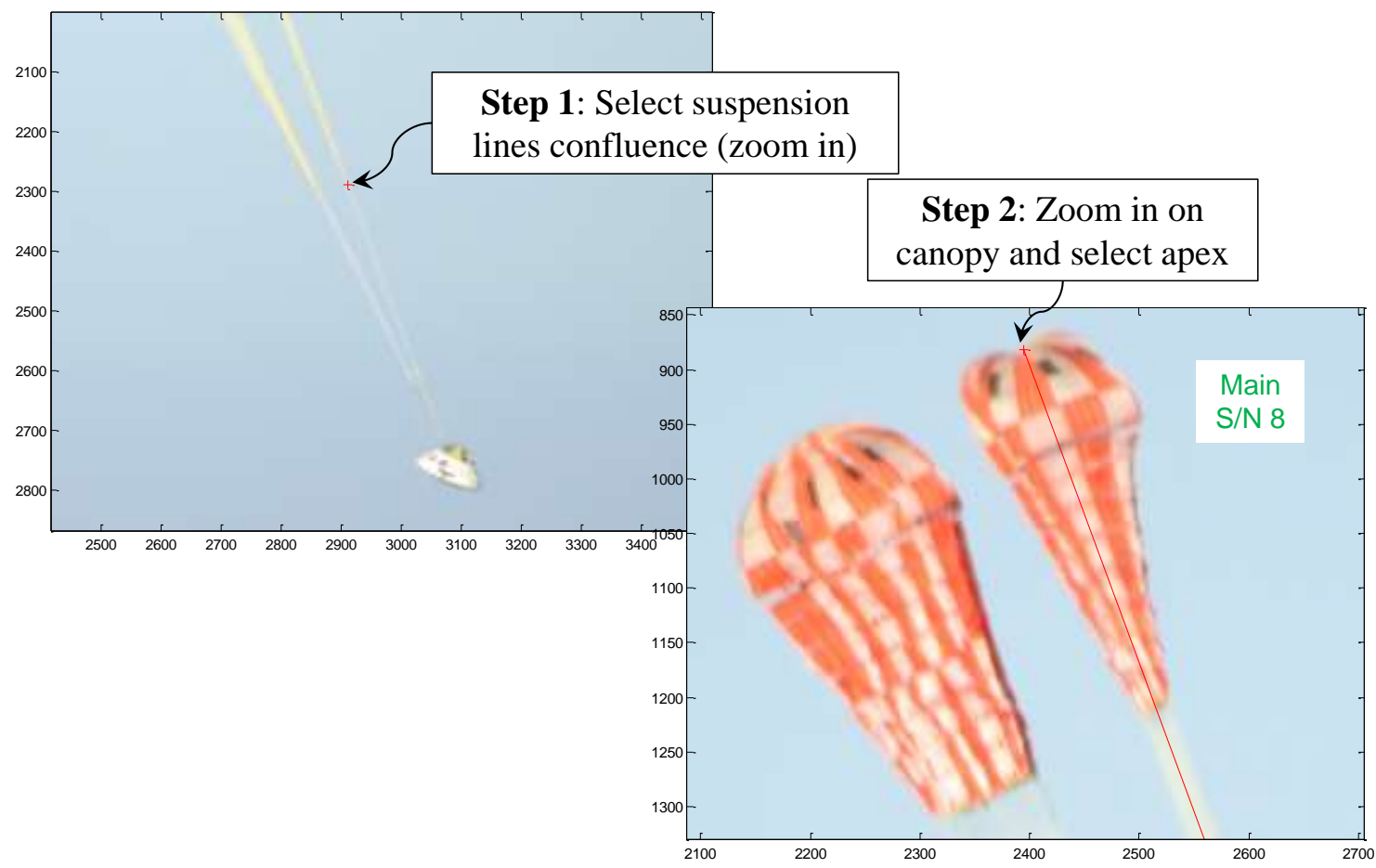

Figure 20. Defining the central axis of a canopy where semi-minor axis is visible.

American Institute of Aeronautics and Astronautics 


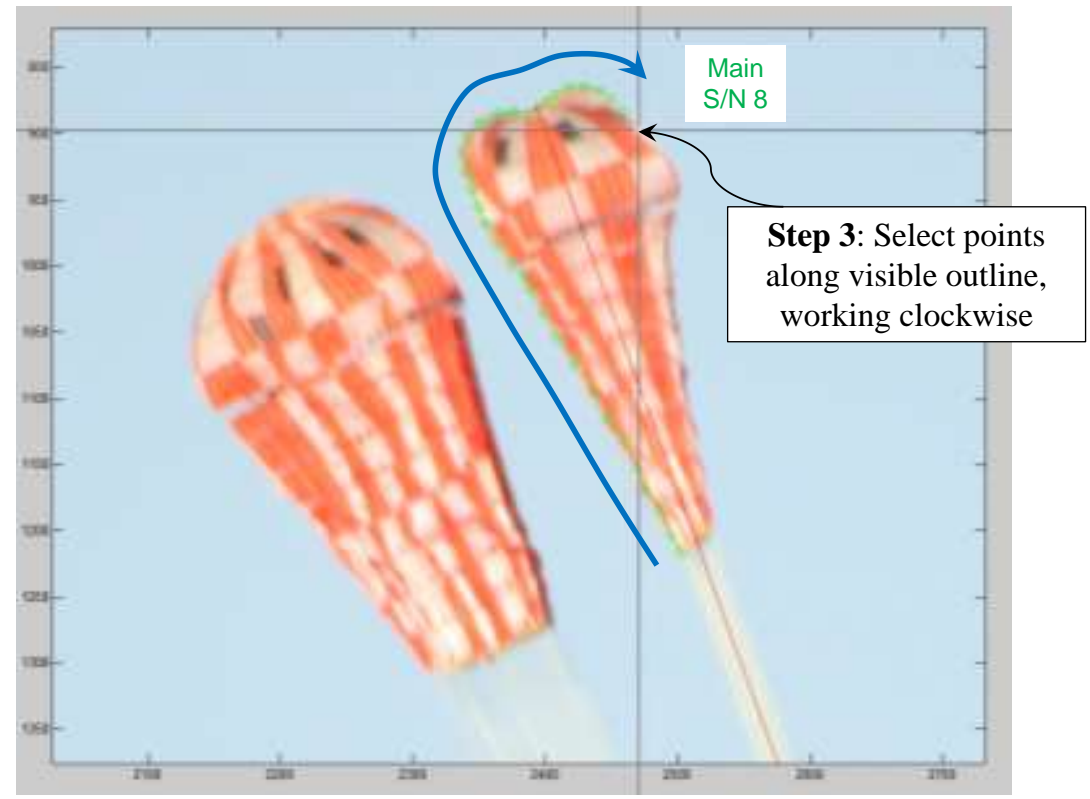

The selection of the canopy outline, shown in Figure 21, is the same as the previous example. The user should proceed in a clockwise direction and the coordinates for all selected points are saved to a data file.

The process of canopy profile rotation, interpolation, and scaling are similar to the previous example. The results are shown in Figure 22. The transformed 2-D profile points are saved to another data file.

Figure 21. Selection of canopy outline for semi-minor axis.

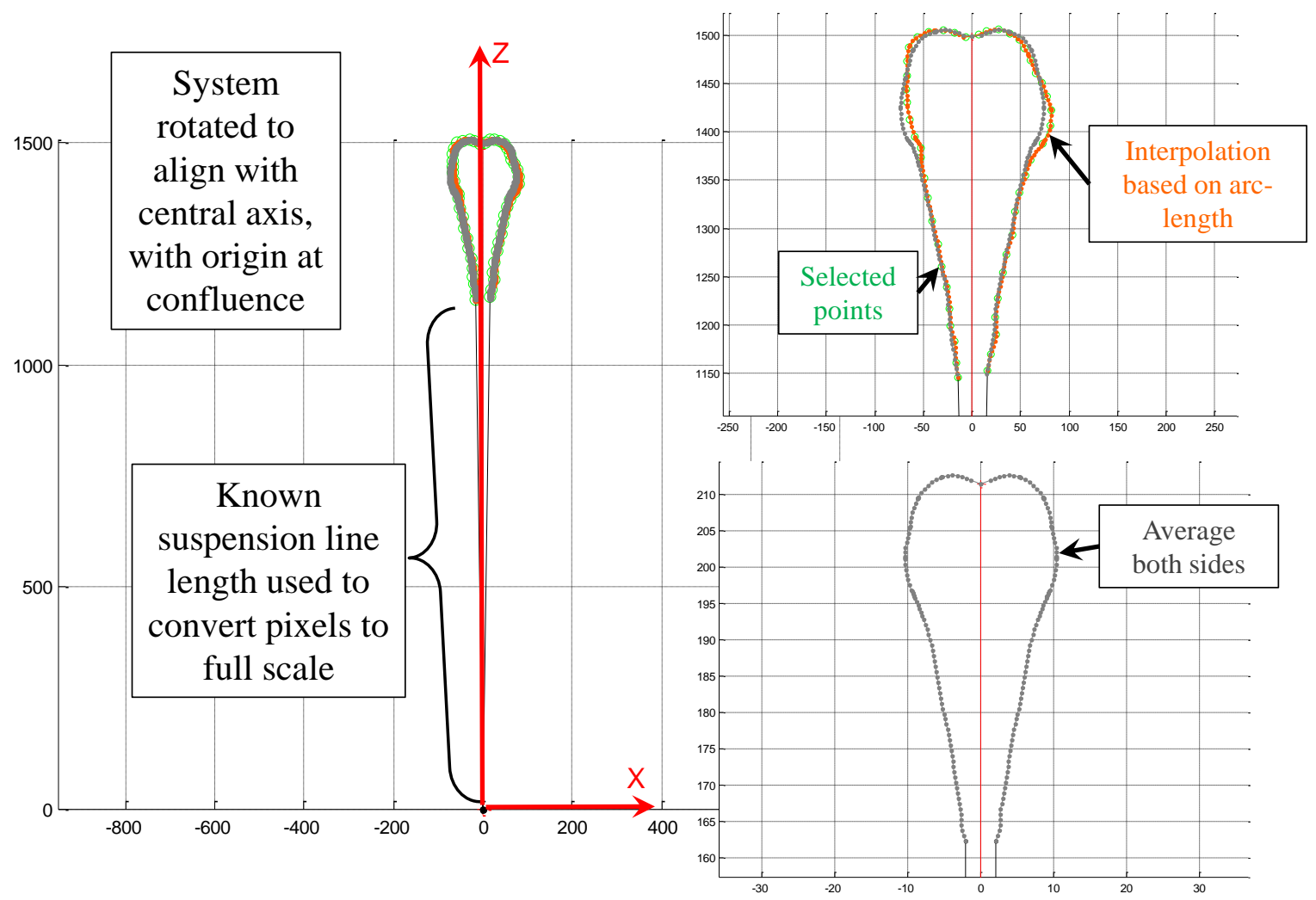

Figure 22. Canopy outline is rotated to central axis, scaled based on known suspension line length, interpolated to a finer resolution based on arc-length, and averaged across both sides.

The lower-order volumes using this profile are shown in Figure 23. The assumption of a circular cross section results in a volume that is too small for this canopy, while the opposite was true for the previous example with the semi-major axis. The elliptical cross-section appears to be a better approximation, though the scaling method tends to under-predict the size of the skirt. The overall fidelity of the 3-D shape is lacking and will not produce desired results.

American Institute of Aeronautics and Astronautics 

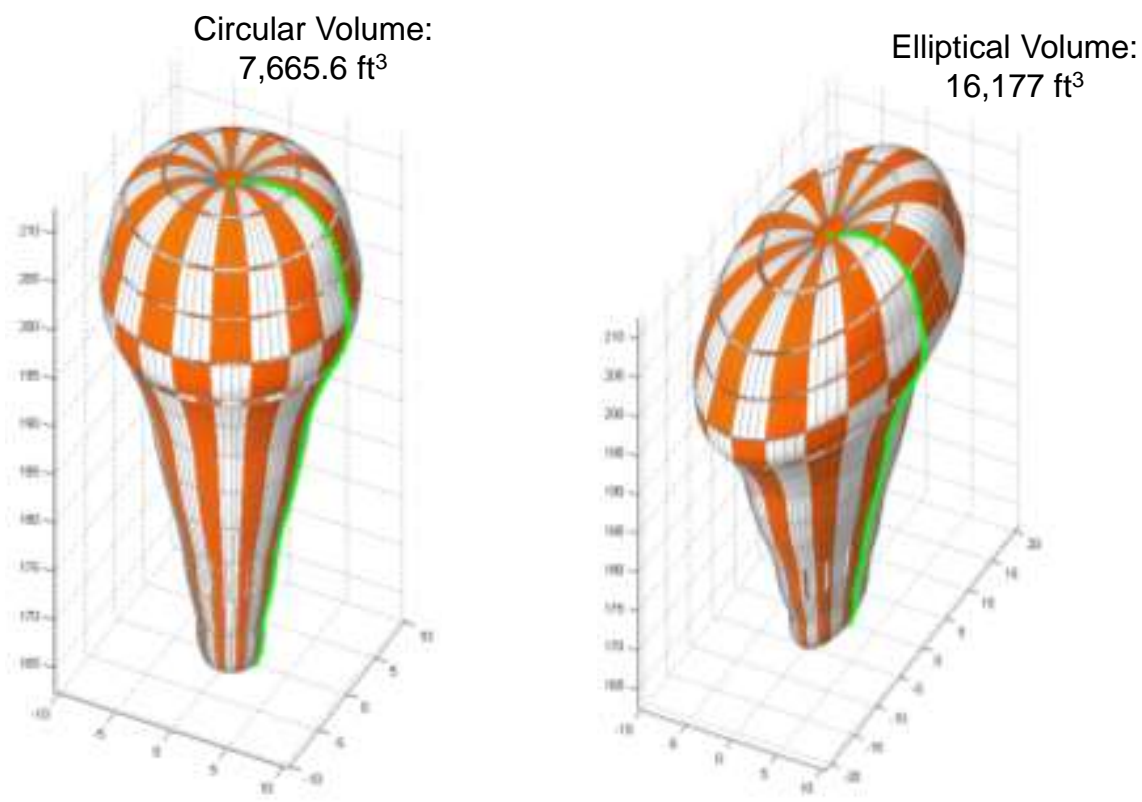

Figure 23. Lower-order volume approximations of semi-minor axis profile.

Scoring of the projected areas from the upward-looking cameras is shown in Figure 24.

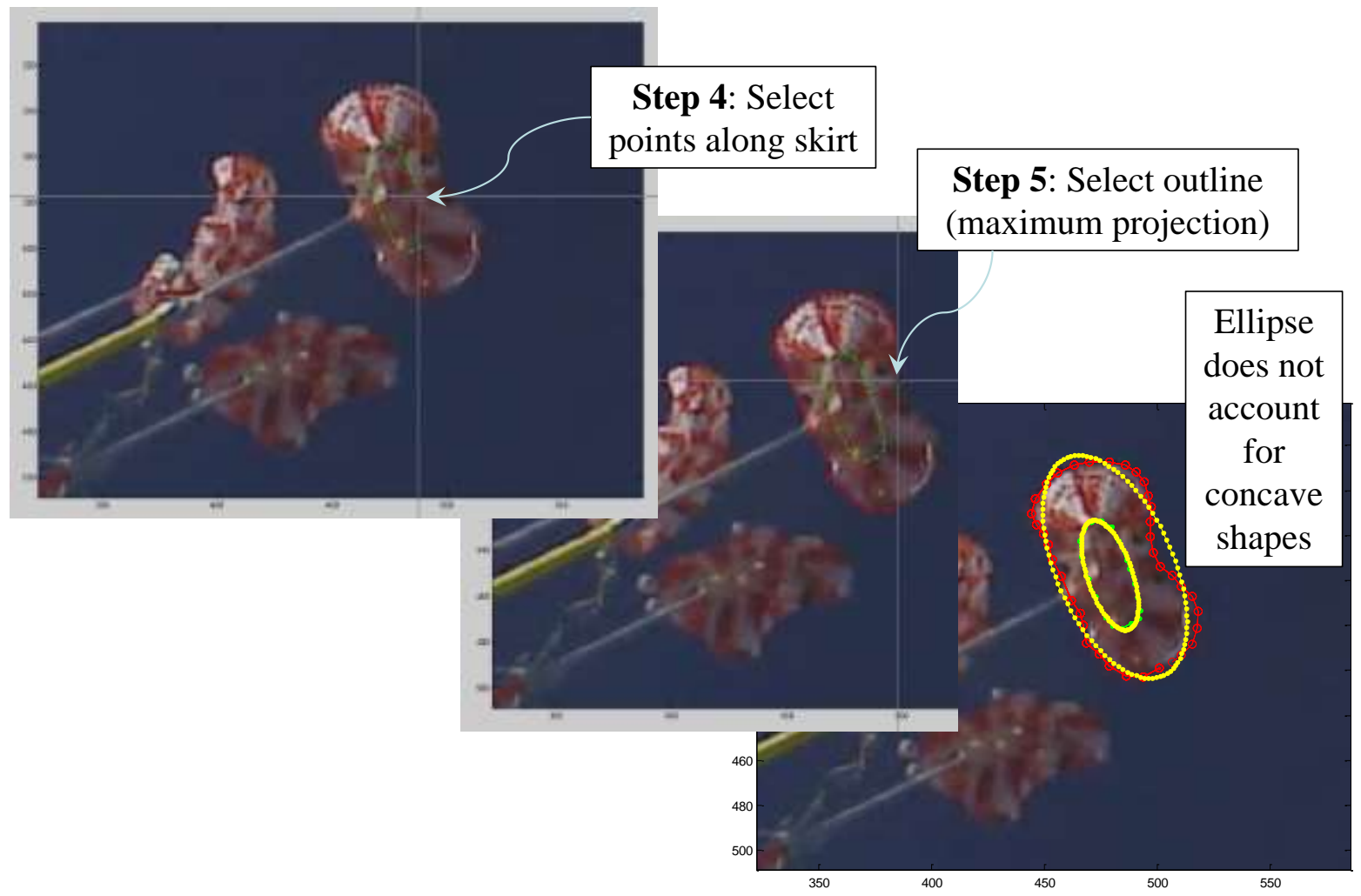

Figure 24. Selection of skirt and maximum projected area points from upward-looking video frame.

The generated irregular shape is shown in Figure 25. In this case, the side profile points are aligned with the minimum radial distance. This allows for concave features on the surface, similar to those observed in flight. 


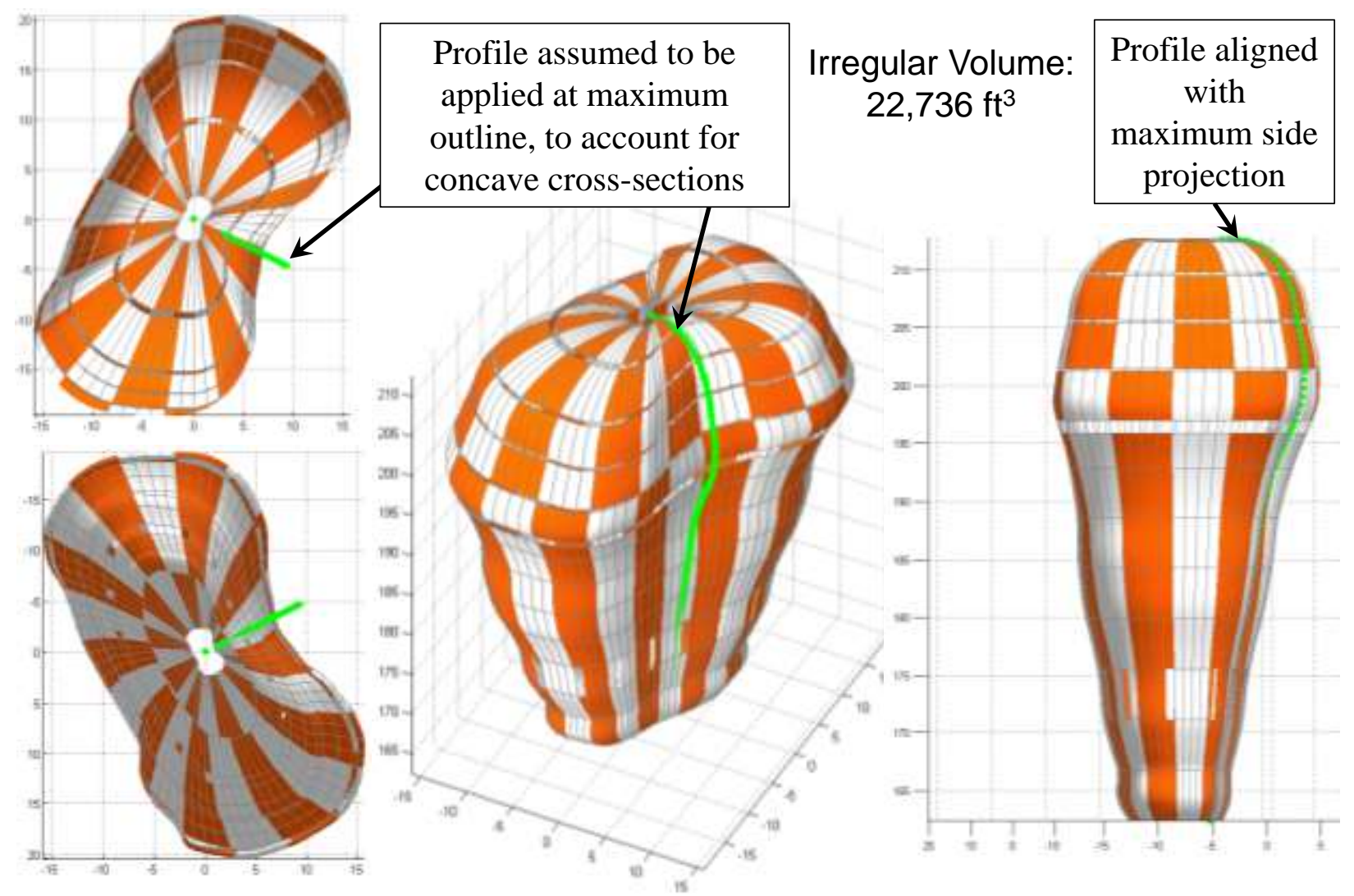

Figure 25. Volume estimate of semi-minor axis example using irregular cross-section approximation.

The 3-D geometry from this method is compared to the original images for several instants of Main S/N 8 during the disreef to full open in Figure 26 through Figure 28. The canopy becomes obscured during this process, so the side profile is based on only the visible side. The 3-D surfaces are acceptable approximations of the actual geometry. 

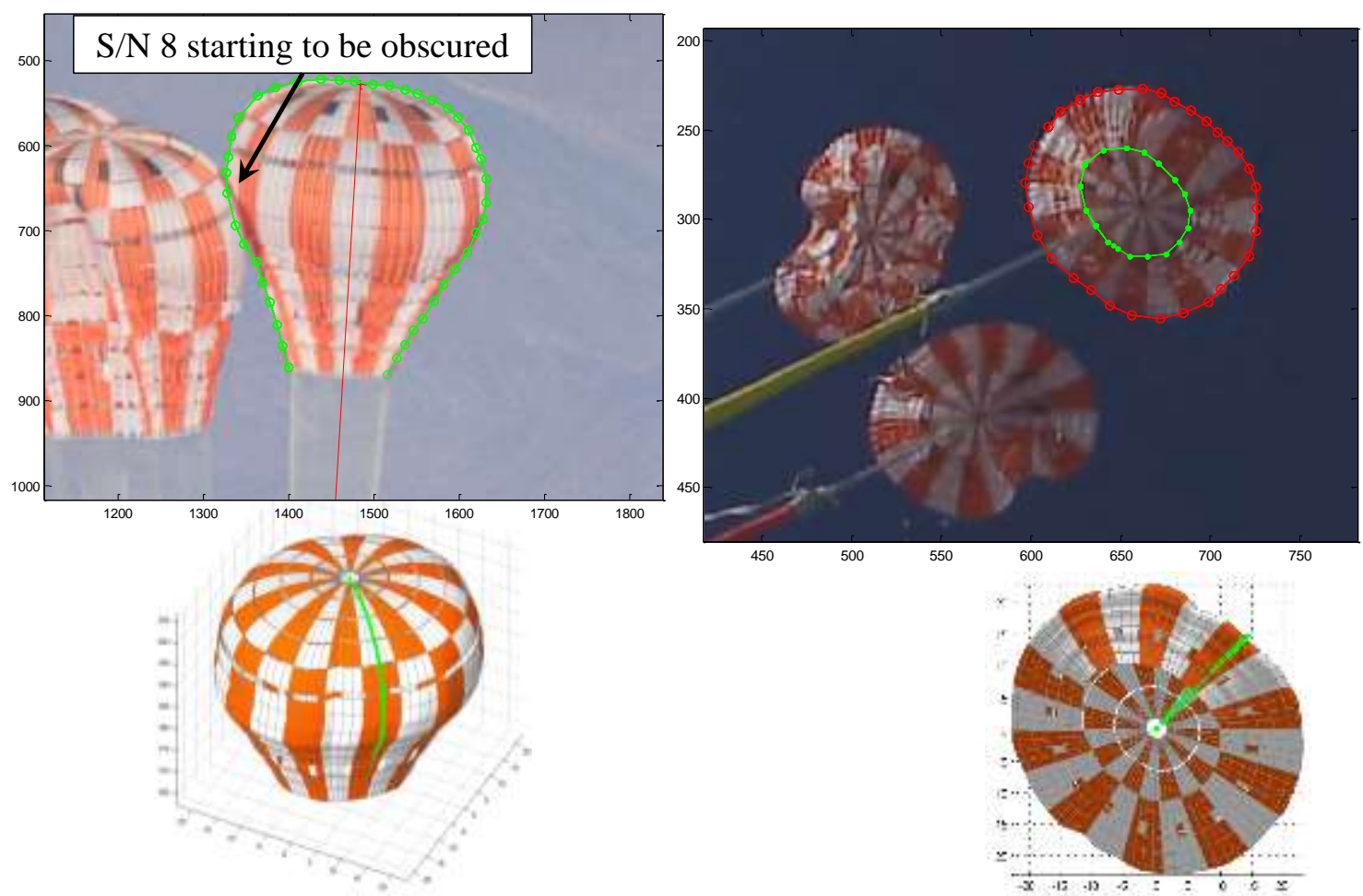

Figure 26. Model of irregular geometry of S/N 8 during second stage.
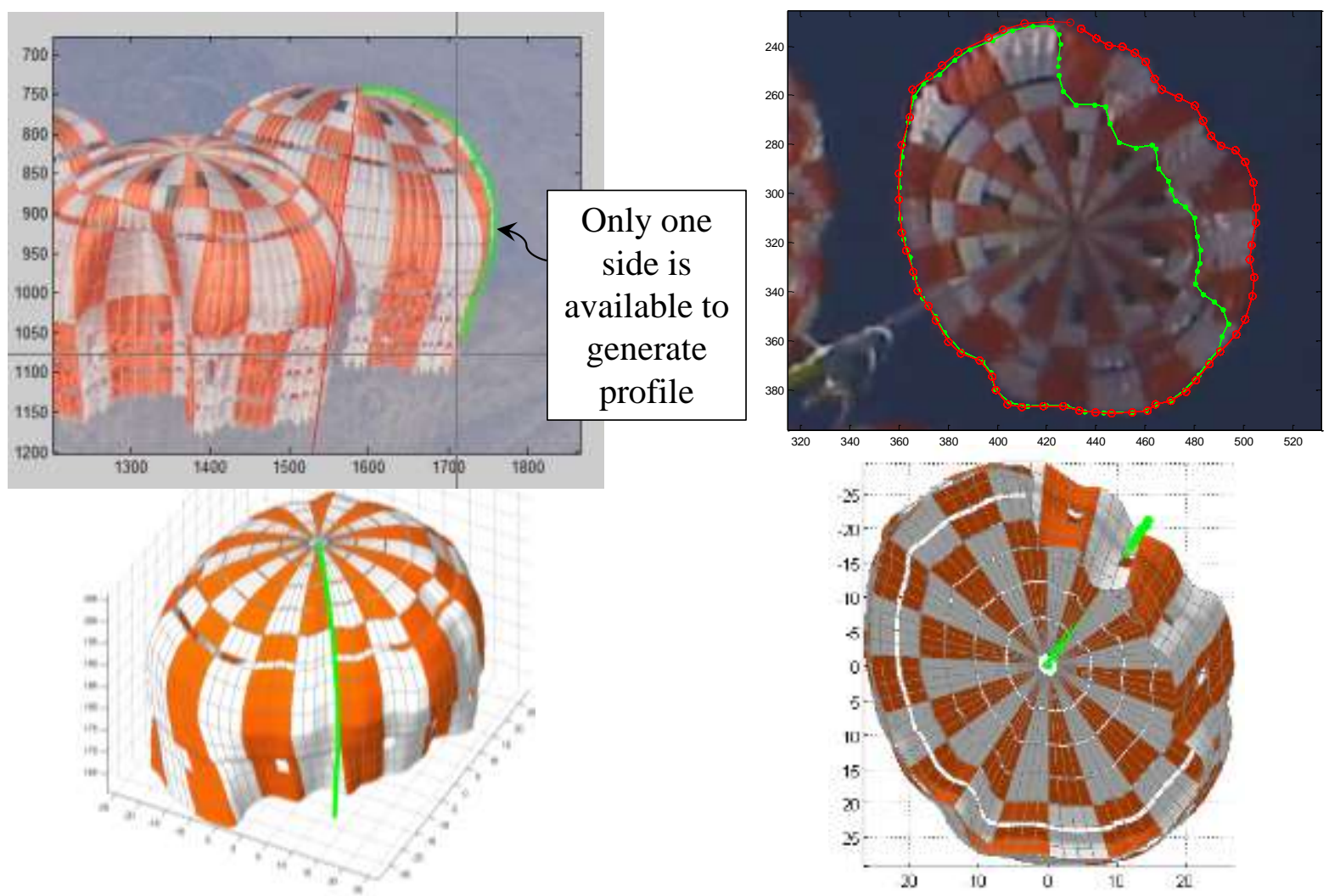

Figure 27. Model of irregular geometry of S/N 8 during disreef to full open. 

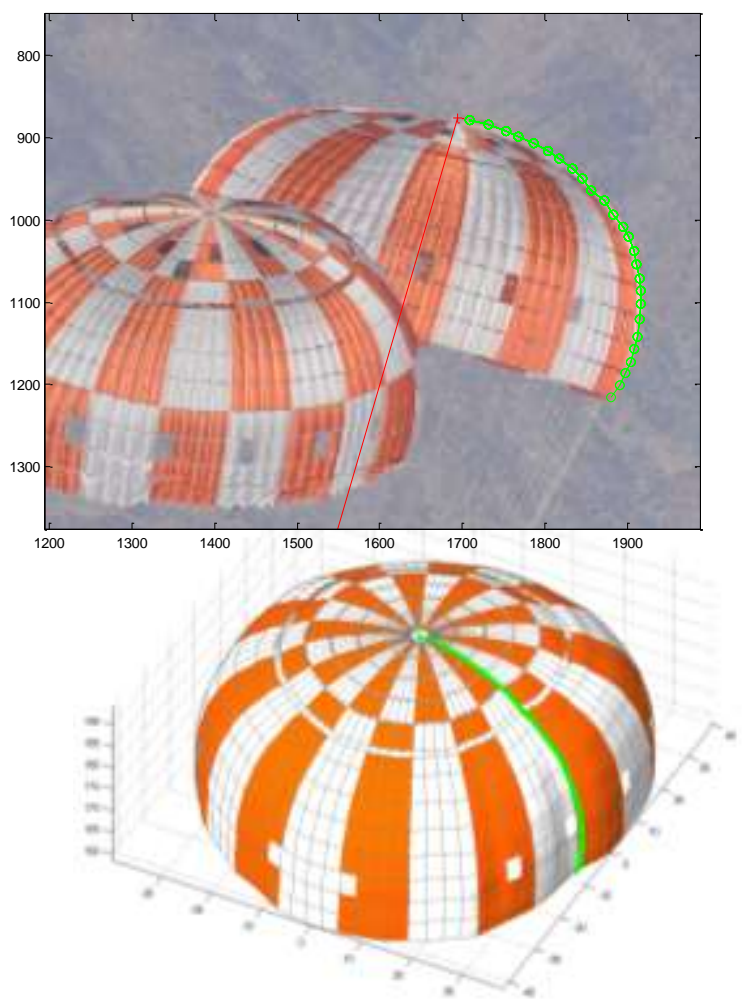
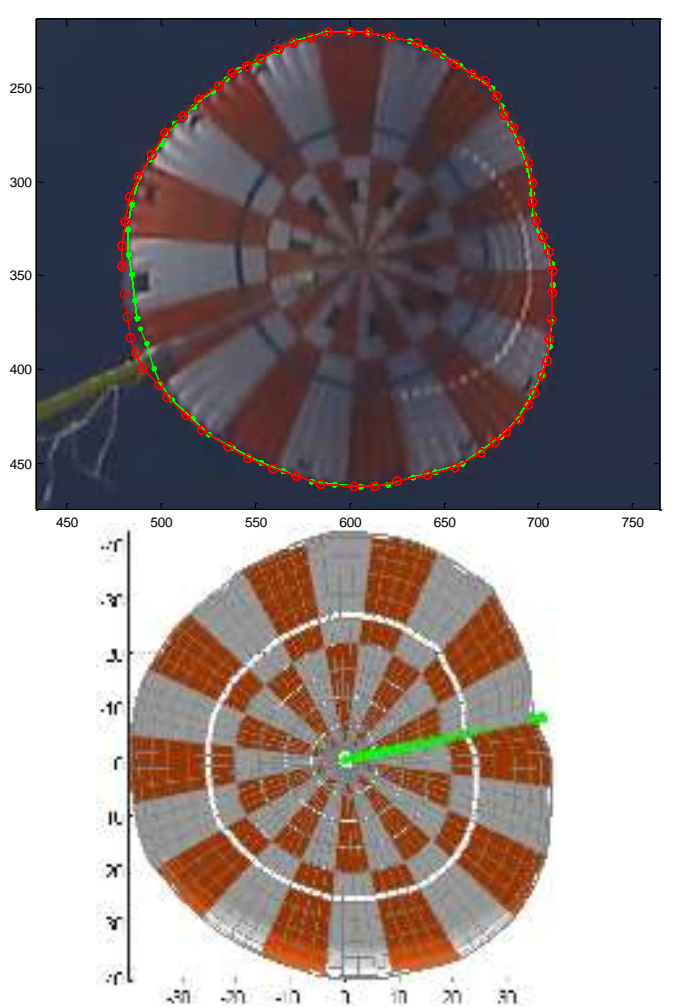

Figure 28. Model of irregular geometry of S/N 8 at full open.

\section{F. Canopy Tilt Compensation}

The parachute system is generally slightly above the chase helicopter during Main deployment, but quickly descends below the helicopter when the canopies reach full open. In addition, cluster interference causes significant fly-out angles during the disreef process. Therefore, the view presented to the camera is often not exactly a true profile view. A method was developed to compensate for the apparent tilt of the canopy axis.

Figure 29 shows an example of the canopy (S/N 7 of CDT-3-13) tilting toward the camera, such that the canopy apex is visible. Instead of selecting points along the outer bounds of the canopy, the user should select points along the radials which bisect the canopy, perpendicular to the viewer. The profile points are replicated and clocked around the central axis to provide a crude wireframe model of the canopy surface. The user is then prompted to enter a tilt angle $(\tau)$, and the wireframe is re-generated. Points on either side of the cutting plane are different colors to clarify tilt orientation. The user then iteratively adjusts the tilt angle until the wireframe model sufficiently matches the curvature of the skirt and uppermost points. The apparent pixel distance of the suspension lines (between the suspension line confluence and the edge of the radials) is then divided by $\cos (\tau)$ in order to calculate a scale factor from pixels to actual distance. The volume is then computed using the irregular shape method. If a profile based on the upper canopy boundary was used instead, the resulting volume estimate would be substantially too large. 


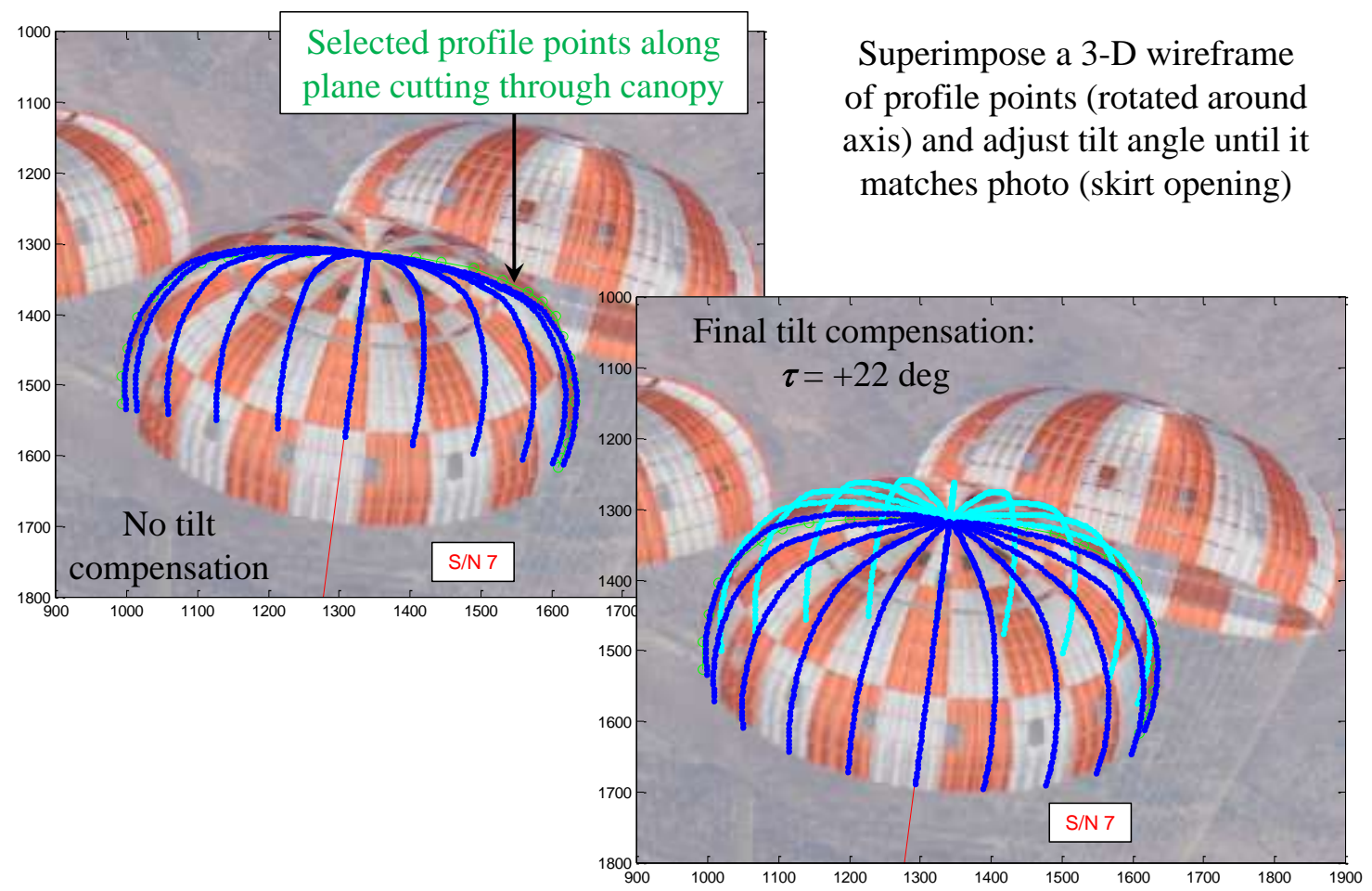

Figure 29. Example of compensation for canopy tilt toward the camera (positive $\tau$ angle).

Figure 30 shows an example from the same test when the canopy (S/N 8) is tilting away from the camera, such that the skirt opening is visible. A wireframe is again superimposed on the canopy and re-generated according to the user-input tilt angle. The user then iteratively adjusts the tilt angle until the wireframe model sufficiently matches the skirt opening. The suspension line distance is again scaled by $1 / \cos (\tau)$. Tilting away from the camera often presents difficulty for the user because the actual points along the top of the canopy are not visible and must be inferred. This takes some trial-and-error for the user become proficient. 


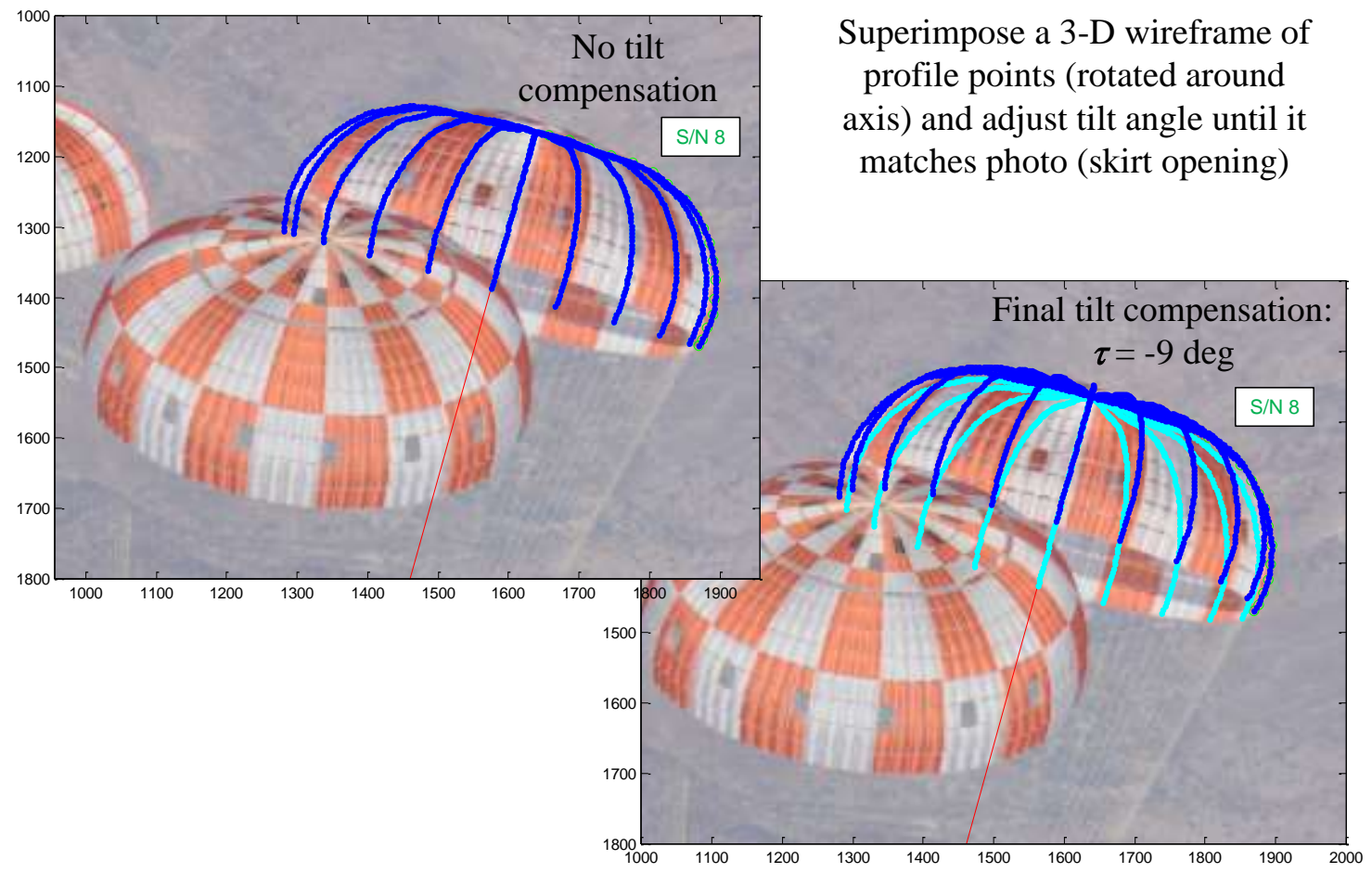

Figure 30. Example of compensation for canopy tilt away from the camera (negative $\tau$ angle).

\section{Selected Flight Data Results}

Although there is no direct way to evaluate the accuracy of the volume calculations for CPAS Main parachutes, there are several intermediate steps which can be validated. During reefed stages, the maximum perimeter of the skirt should be no larger than the length of the reefing line, $\mathrm{L}_{\mathrm{r}}$. After disreef to full open, it is possible to compare the computed skirt perimeter and projected area with the photogrammetry performed by the JSC KX Image Science \& Analysis Group. That analysis includes compensations for both radial lens distortion and perspective distortions, which have not been applied in the current study.

\section{A. CDT-3-2}

The second EDU test, CDT-3-2, descended under two Mains. 3-D surfaces were generated for both canopies and are compared to the original images for three stages in Figure 31 through Figure 33. The estimated skirt perimeter and projected area data compare well with the KX analysis in Figure 34 and Figure 35, respectively. This should increase confidence in the computed enclosed volume data plotted in Figure 36. 


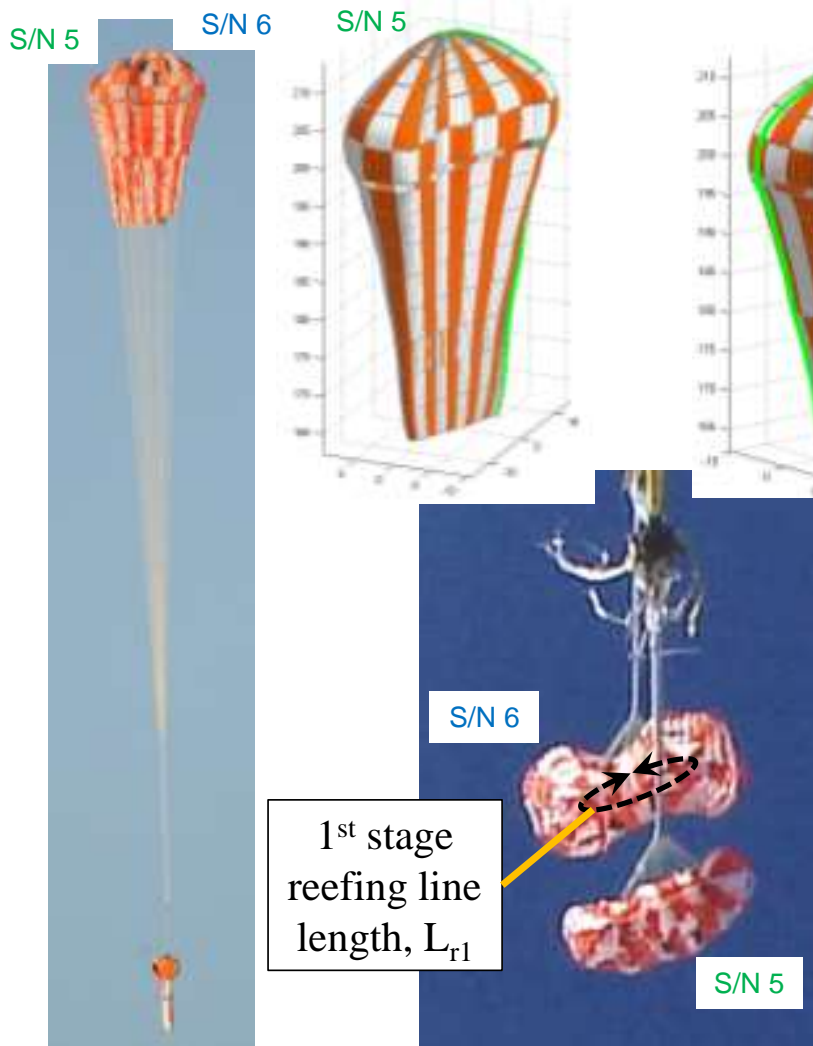

$\mathrm{S} / \mathrm{N} 6$

Figure 31. CDT-3-2 $1^{\text {st }}$ stage (jsc2011e218254_nr.JPG).

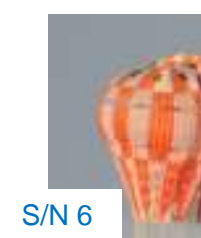

\section{S/N 5}
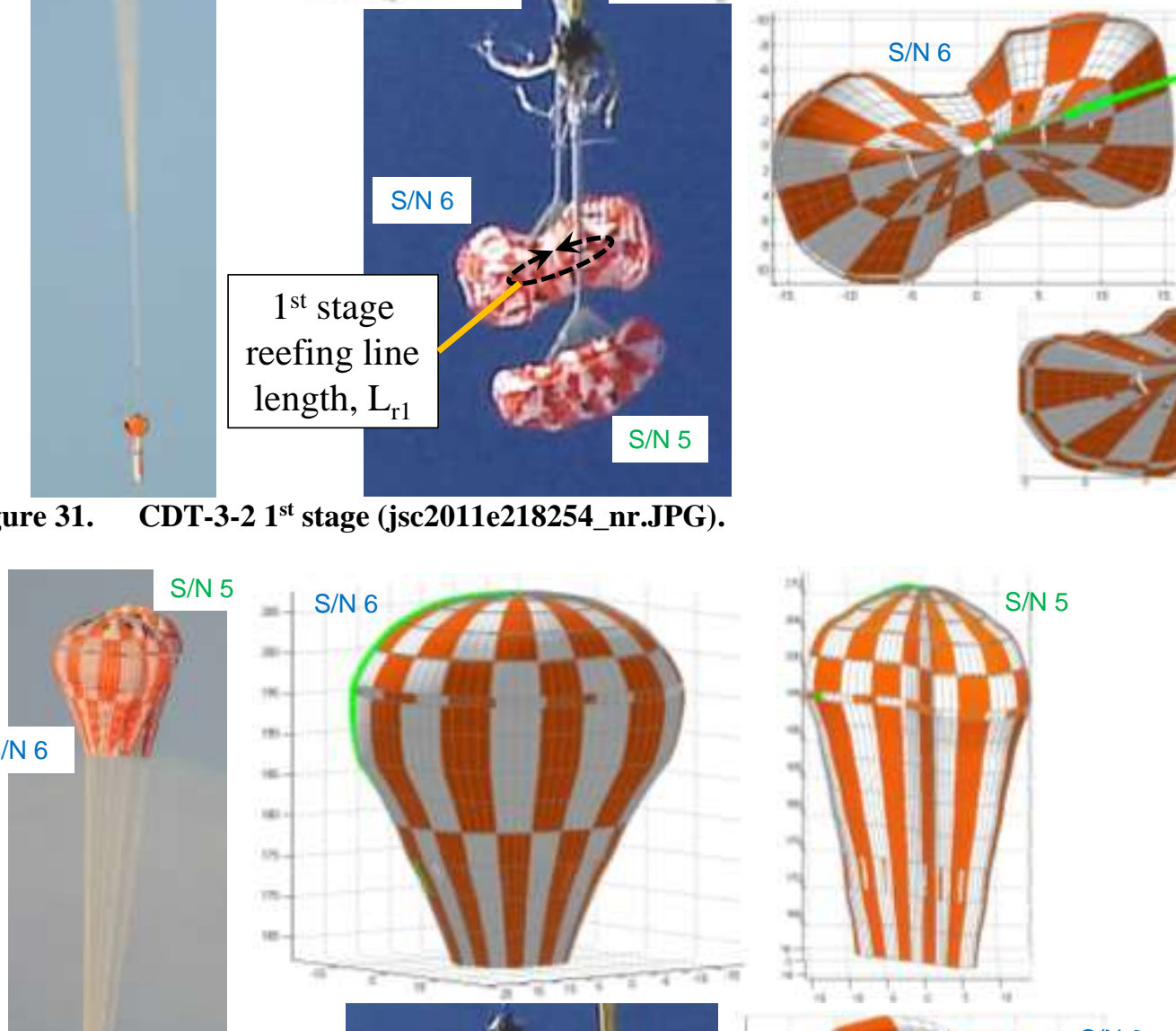

$\mathrm{S} / \mathrm{N} 5$
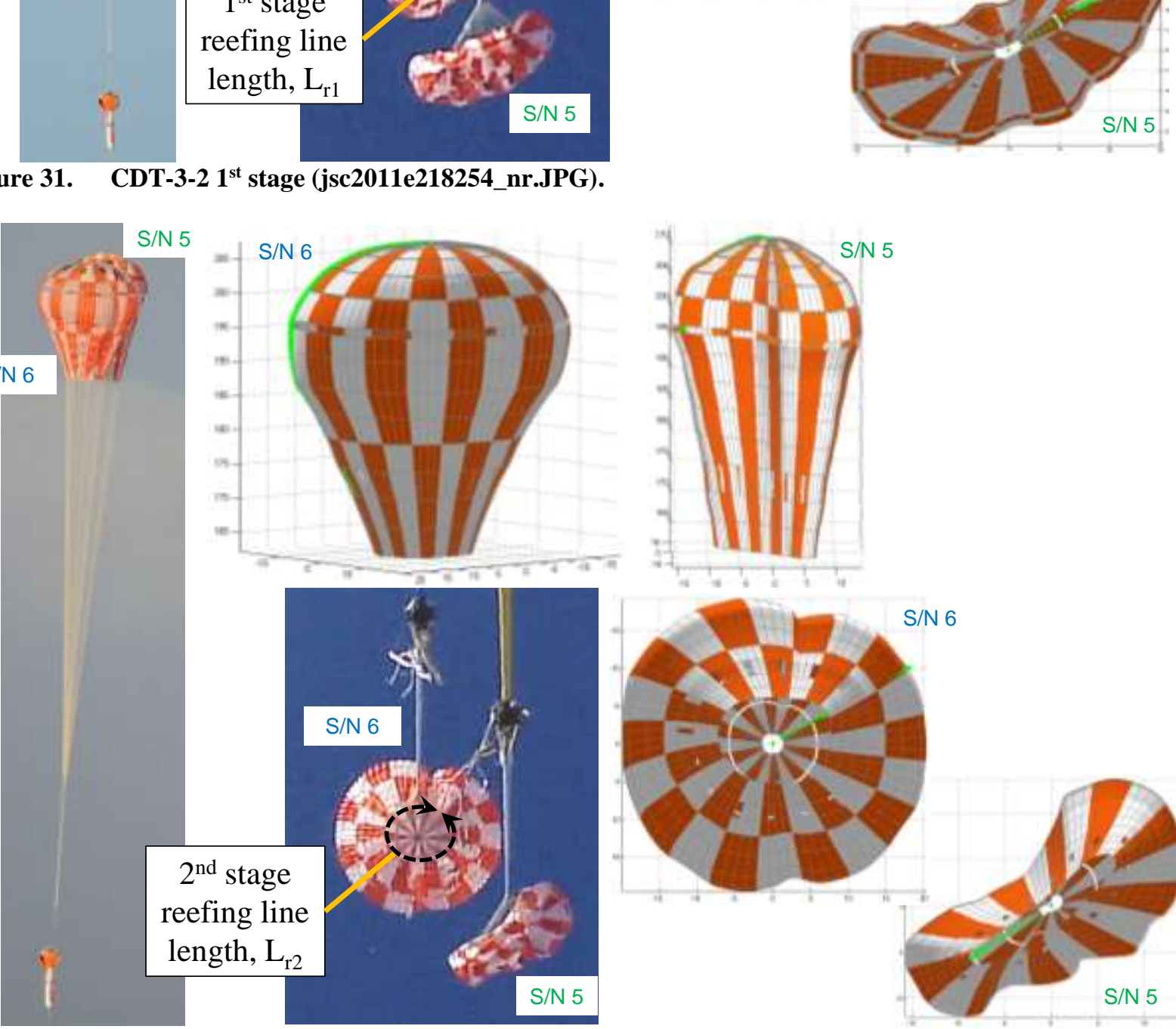

S/N 6

Figure 32. CDT-3-2 $2^{\text {nd }}$ stage (jsc2011e218278_nr.JPG).

American Institute of Aeronautics and Astronautics 


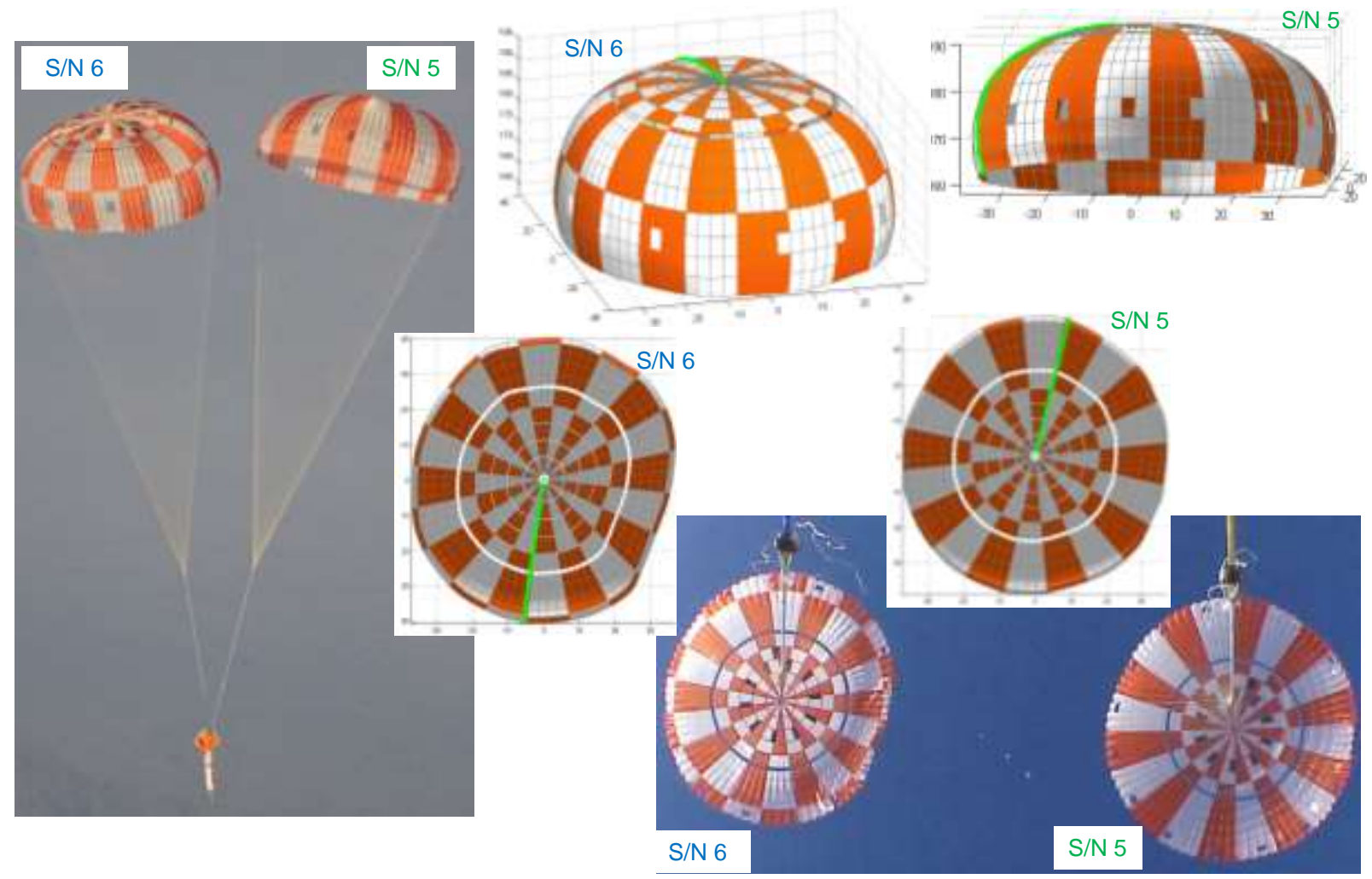

Figure 33. CDT-3-2 full open (jsc2011e218300_nr.JPG).

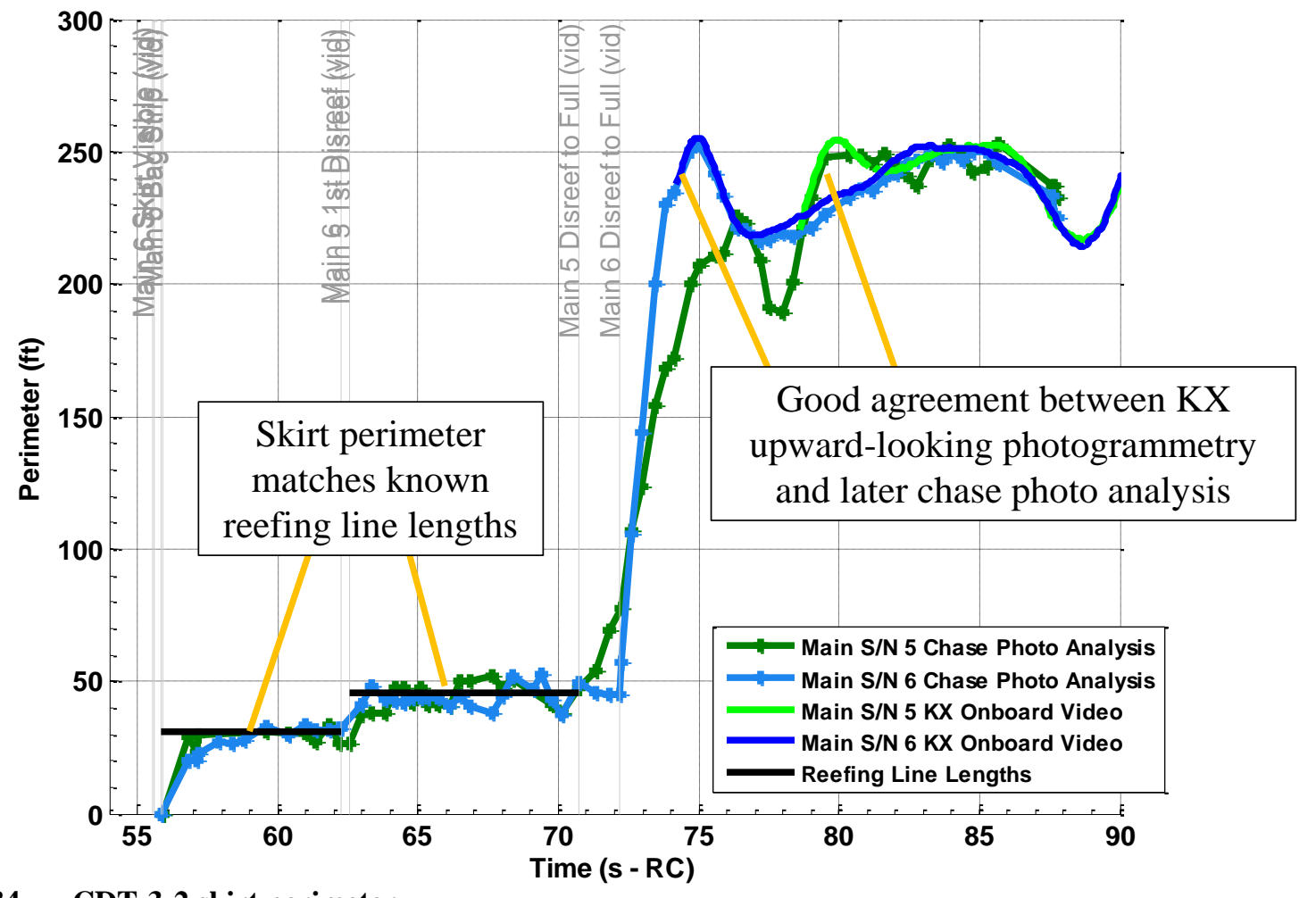

Figure 34. CDT-3-2 skirt perimeter. 


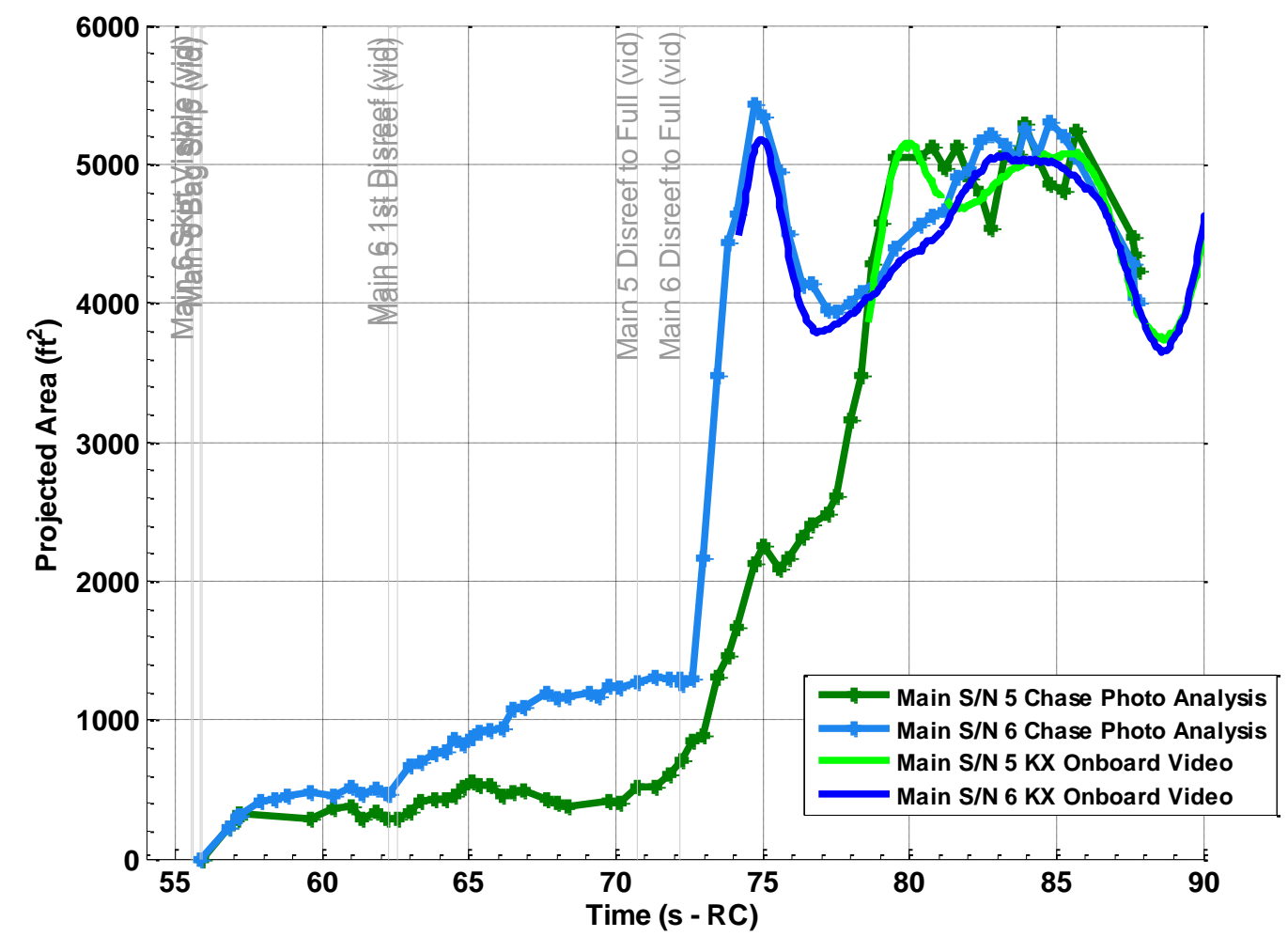

Figure 35. CDT-3-2 maximum projected area.

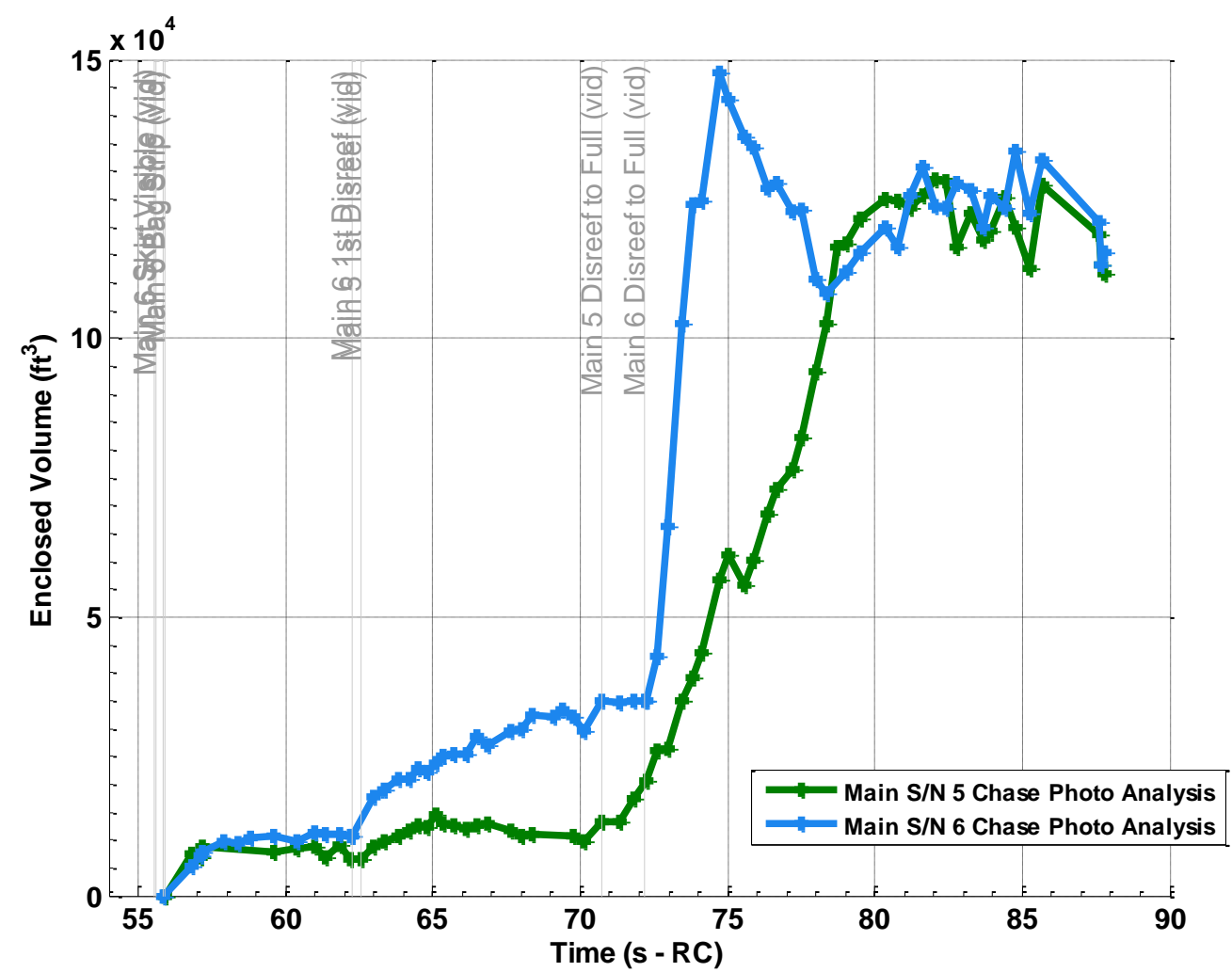

Figure 36. CDT-3-2 enclosed volume.

American Institute of Aeronautics and Astronautics 


\section{B. CDT-3-4}

CDT-3-4 was a 3-Main test where one of the canopies (S/N 4) skipped second stage via a pre-cut reefing line. ${ }^{13}$ One of the non-skipping canopies was almost always obscured while the other was visible in the first stage and full open. The 3-D models are compared to the images in Figure 37 and Figure 38.
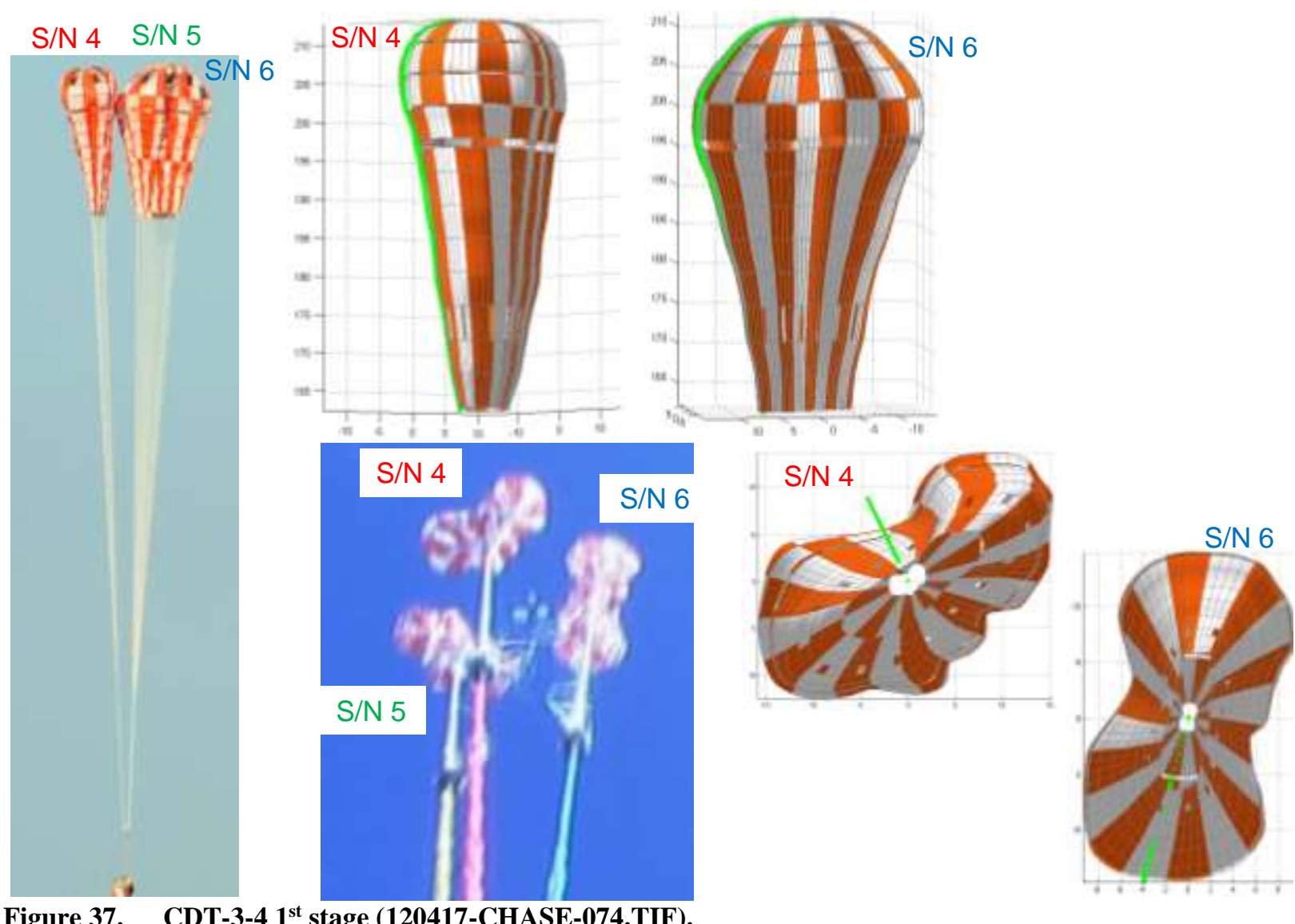

Figure 37. CDT-3-4 $1^{\text {st }}$ stage (120417-CHASE-074.TIF). 

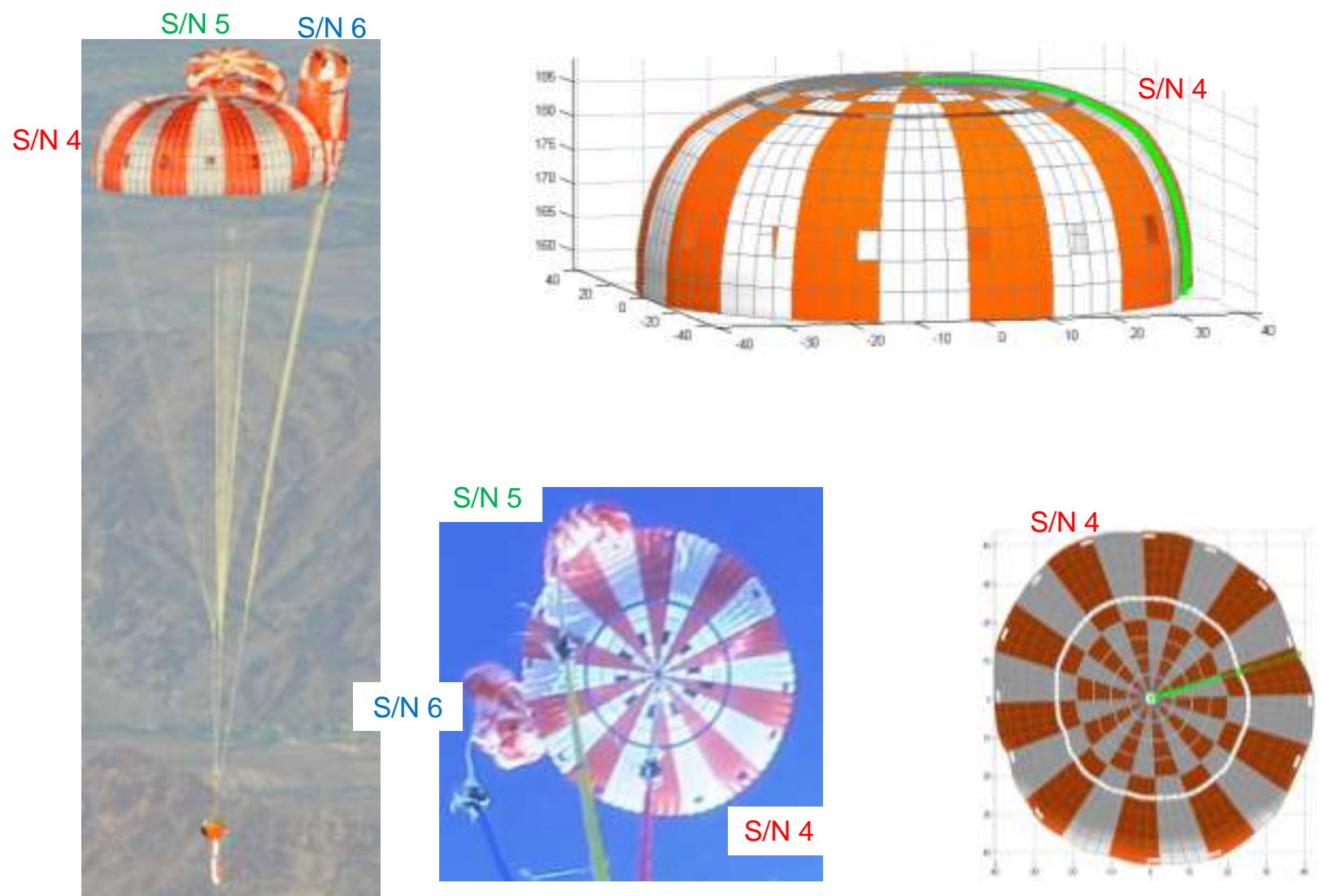

Figure 38. CDT-3-4 skip $2^{\text {nd }}$ stage (120417-CHASE-084.TIF).

The computed perimeter is plotted in Figure 39. The first stage perimeter for $\mathrm{S} / \mathrm{N} 4$ is consistently larger than the known reefing line length, perhaps indicating a bias in the scale factor used in the side view photo. Although the frequency of chase photos was relatively low, the data make a good transition to the KX photogrammetric results after each parachute disreefs to full open. Likewise, the projected area estimates compare favorably in Figure 40. The enclosed volume estimates are plotted in Figure 41. 


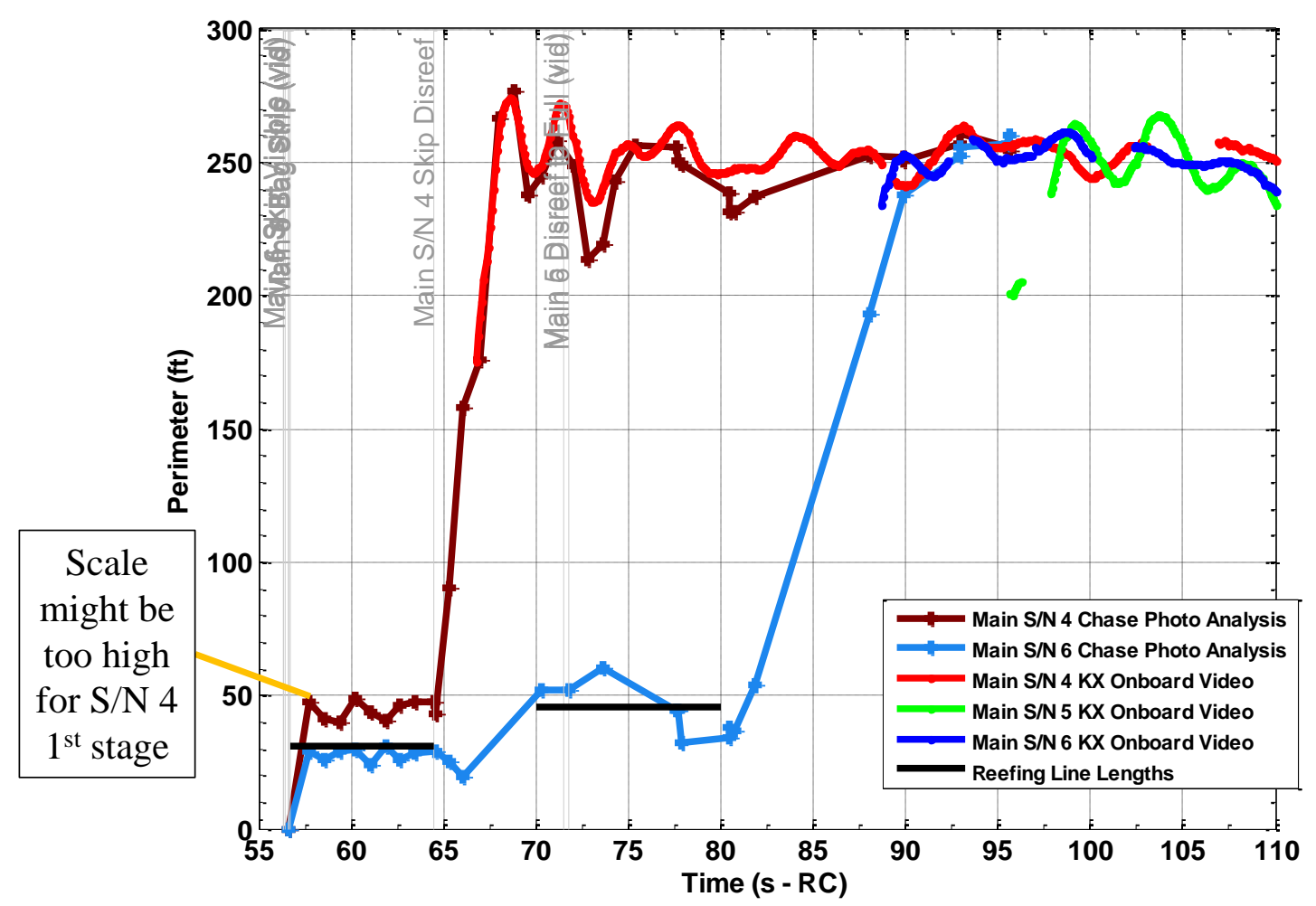

Figure 39. CDT-3-4 skirt perimeter.

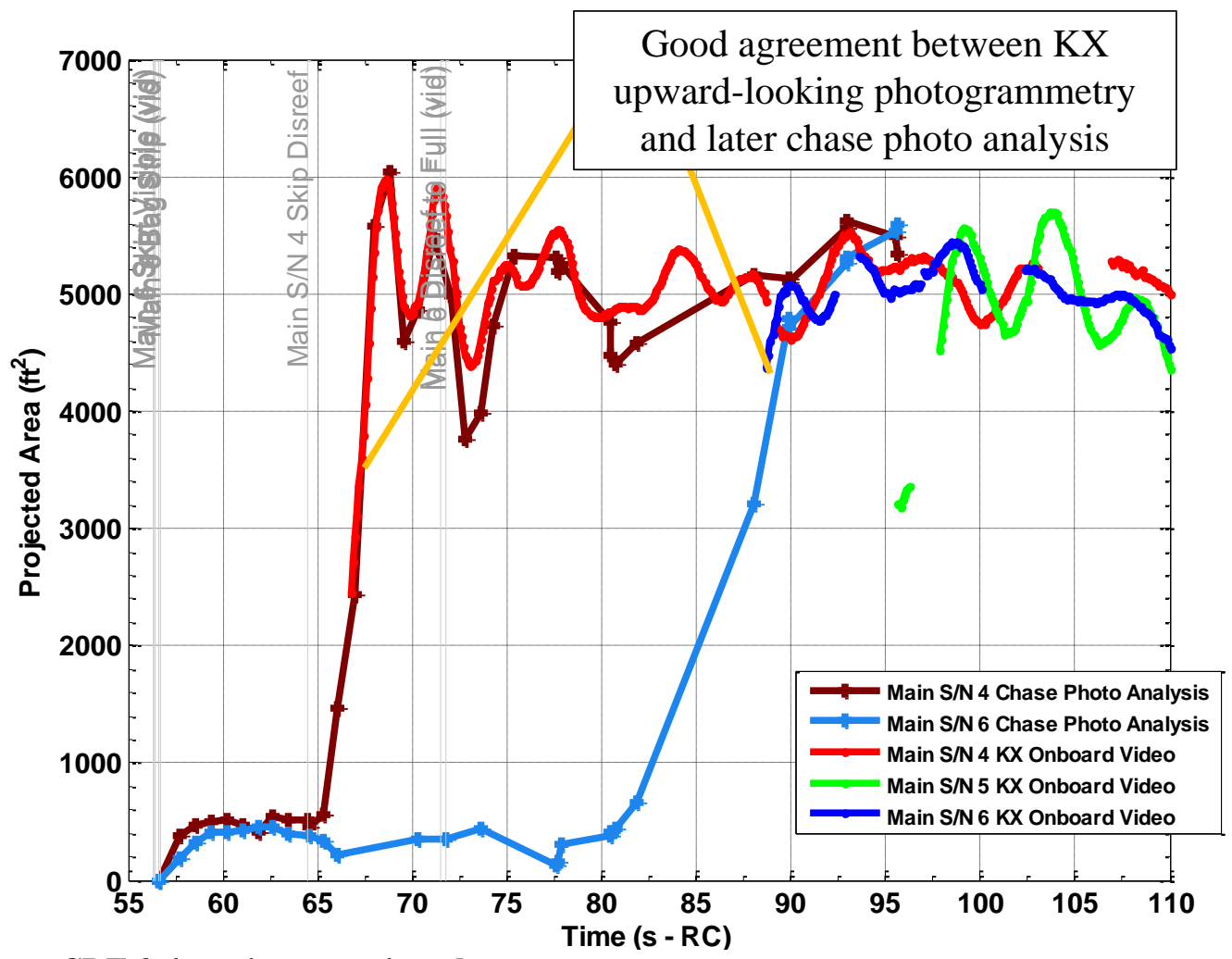

Figure 40. CDT-3-4 maximum projected area.

American Institute of Aeronautics and Astronautics 


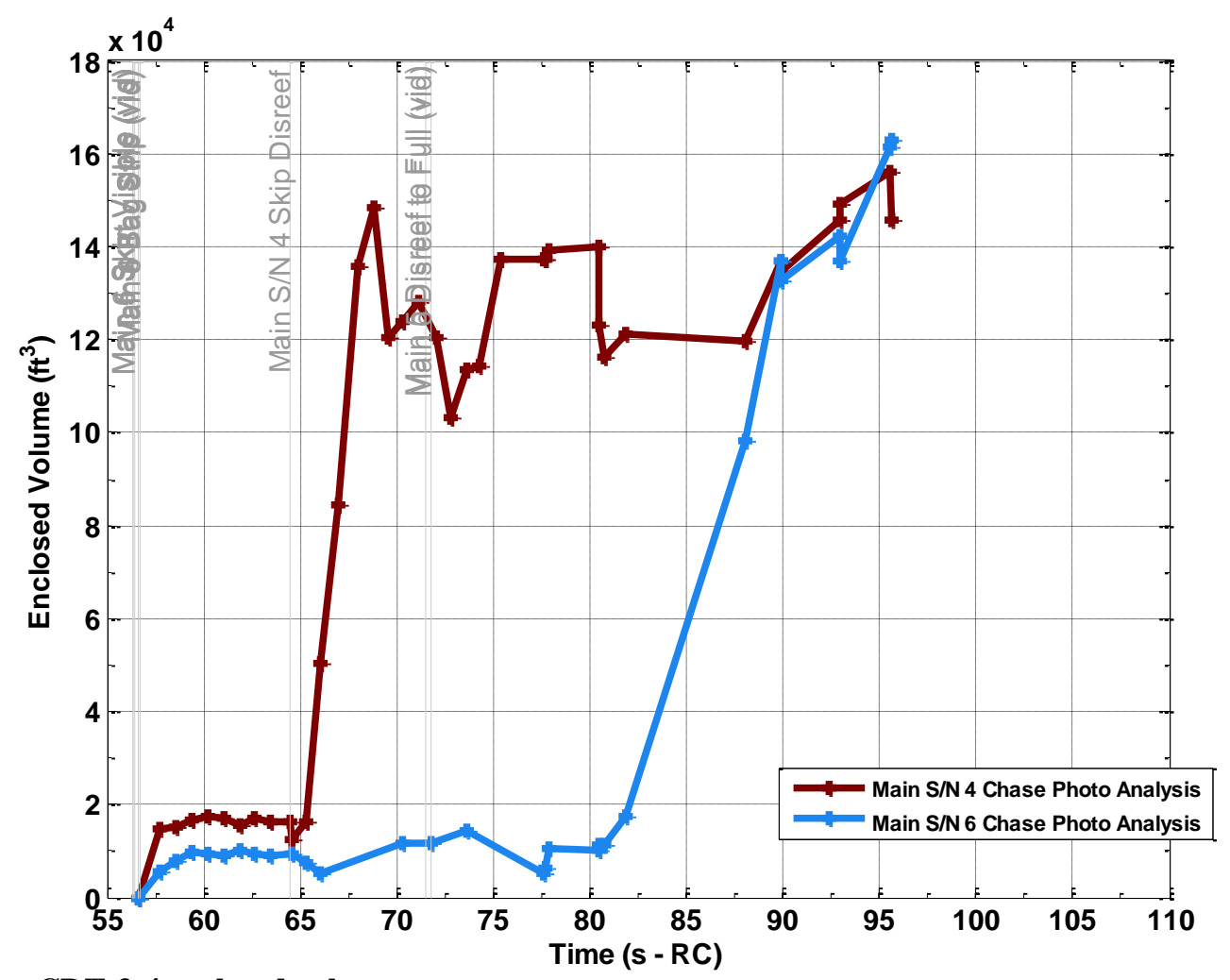

Figure 41. CDT-3-4 enclosed volume.

\section{Conclusion}

A method was developed to describe the irregular 3-D shape of inflating CPAS Main parachutes in a cluster using side views from chase aircraft photos and upward-looking HD video. This allows for estimation of the time varying enclosed volume, which is essential in computing added mass (described in a companion paper). This method was indirectly validated by comparing perimeter and projected area with known line lengths and/or high quality photogrammetry. To date, full open volume estimates vary between about 100,000 and 160,000 $\mathrm{ft}^{3}$ per parachute.

The method was refined by accounting for the irregular canopy shape and apparent tilt angle of the canopy relative to the camera. The process could be further improved by allowing for arbitrary roll angles along the central axis in the wireframe representation, rather than assuming each canopy presents either a semi-major or semi-minor axis. The process could also adapt some methods used by the KX photogrammetry such as automated point tracking and compensation for visual distortion.

The 3-D models may be useful in other applications. High fidelity shapes could be combined with loads and aerodynamic data to estimate the stresses in canopy fabric and reefing lines. These shapes may also be used to define grids for CFD analysis.

\section{Acknowledgments}

The author would like to acknowledge the efforts of summer intern Sumeet Vadodkar in developing these methods and scoring photographs. The photogrammetric data from upward-looking cameras used for comparison were reduced by David Bretz and others with the JSC-KX Image Science \& Analysis Group. The author would also like to thank the photographers and chase aircraft operators from NASA and YPG, who have been responsive and accommodating in delivering quality visuals. All chase helicopter photos since CDT-3-2 were taken by James Blair (NASA JSC contractor).

\section{References}

${ }^{1}$ Ray, E., "Isolating Added Mass Load Components of CPAS Main Clusters," (submitted for publication).

American Institute of Aeronautics and Astronautics 
${ }^{2}$ Fraire, U., Dearman, J., and Morris, A., "Proposed Framework for Determining Added Mass of Orion Drogue Parachutes," $21^{s t}$ AIAA Aerodynamic Decelerator Systems Technology Conference and Seminar, Dublin, Ireland, May 2011, AIAA paper 20112546.

${ }^{3}$ Ray, E. and Morris, A. L., "Measurement of CPAS Main Parachute Rate of Descent," $21^{\text {st }}$ AIAA Aerodynamic Decelerator Systems Technology Conference and Seminar, Dublin, Ireland, May 2011, AIAA paper 2011-2545.

${ }^{4}$ Ray, E., "Reconstruction of Orion EDU Parachute Inflation Loads," $22^{\text {nd }}$ AIAA Aerodynamic Decelerator Systems Technology Conference, Daytona Beach, Florida, March 2013, AIAA paper 2013-1260.

${ }^{5}$ Ray, E., Bretz, D. R., and Morris, A. L., "Photogrammetric Analysis of CPAS Main Parachutes," $21^{s t}$ AIAA Aerodynamic Decelerator Systems Technology Conference and Seminar, Dublin, Ireland, May 2011, AIAA paper 2011-2538.

${ }^{6}$ Ray, E. and Bretz, D. R., "Improved CPAS Photogrammetric Capabilities for Engineering Development Unit (EDU) Testing," $22^{\text {nd }}$ AIAA Aerodynamic Decelerator Systems Technology Conference, Daytona Beach, Florida, March 2013, AIAA paper 20131258.

${ }^{7}$ Kidane, B. A., "Parachute Drag Area Using Added Mass as Related to Canopy Geometry," $20^{\text {th }}$ AIAA Aerodynamic Decelerator Systems Technology Conference and Seminar, Seattle, Washington, May 2009, AIAA paper 2009-2942.

${ }^{8}$ Morris, A. L., Bledsoe, K. J., Fraire, U., et al., "Summary of CPAS Gen II Testing Analysis Results," $21^{\text {st }}$ AIAA Aerodynamic Decelerator Systems Technology Conference and Seminar, Dublin, Ireland, May 2011, AIAA paper 2011-2585.

9 Ray, E. and Machín, R. A., "Pendulum Motion in Main Parachute Clusters," $23^{\text {rd }}$ AIAA Aerodynamic Decelerator Systems Technology Conference, Daytona Beach, Florida, March 2015, submitted for publication.

${ }^{10}$ Ray, E. S., "Reefing Line Tension in CPAS Main Parachute Clusters," $22^{\text {nd }}$ AIAA Aerodynamic Decelerator Systems Technology Conference, Daytona Beach, Florida, March 2013, AIAA paper 2013-1393.

${ }^{11}$ D'Errico, J., “interparc.m,” Matlab File Exchange, https://www.mathworks.com/matlabcentral/fileexchange/34874-interparc, February 2012.

${ }^{12}$ Brown, R., "fitellipse.m” Matlab File Exchange, https://www.mathworks.com/matlabcentral/fileexchange/15125-fitellipse-m, May 2007.

13 Varela, J. G., and Ray, E., "Skipped Stage Modeling and Testing of the CPAS Main Parachutes," 22 $2^{\text {nd }}$ AIAA Aerodynamic Decelerator Systems Technology Conference, Daytona Beach, Florida, March 2013, AIAA paper 2013-1257.

American Institute of Aeronautics and Astronautics 